\title{
An interannual link between Arctic sea-ice cover and the North Atlantic Oscillation
}

\author{
Mihaela Caian $^{1} \cdot$ Torben Koenigk $^{1} \cdot$ Ralf Döscher $^{1} \cdot$ Abhay Devasthale $^{1}$
}

Received: 20 November 2014 / Accepted: 3 March 2017 / Published online: 25 March 2017

(c) The Author(s) 2017. This article is an open access publication

\begin{abstract}
This work investigates links between Arctic surface variability and the phases of the winter (DJF) North Atlantic Oscillation (NAO) on interannual time-scales. The analysis is based on ERA-reanalysis and model data from the EC-Earth global climate model. Our study emphasizes a mode of sea-ice cover variability that leads the NAO index by 1 year. The mechanism of this leading is based on persistent surface forcing by quasi-stationary meridional thermal gradients. Associated thermal winds lead a slow adjustment of the pressure in the following winter, which in turn feeds-back on the propagation of sea-ice anomalies. The pattern of the sea-ice mode leading NAO has positive anomalies over key areas of South-Davis Strait-Labrador Sea, the Barents Sea and the Laptev-Ohkostsk seas, associated to a high pressure anomaly over the Canadian Archipelago-Baffin Bay and the Laptev-East-Siberian seas. These anomalies create a quasi-annular, quasi-steady, positive gradient of sea-ice anomalies about coastal line (when leading the positive NAO phase) and force a cyclonic vorticity anomaly over the Arctic in the following winter. During recent decades in spite of slight shifts in the modes' spectral properties, the same leading mechanism remains valid. Encouraging, actual models appear to reproduce the
\end{abstract}

In the original publication of this article, the second co-author name has been published incorrectly; this error has now been corrected.

Electronic supplementary material The online version of this article (doi:10.1007/s00382-017-3618-9) contains supplementary material, which is available to authorized users.

Mihaela Caian

mihaela.caian@smhi.se

1 Rossby Centre, Swedish Meteorological and Hydrological Institute, Norrköping, Sweden same mechanism leading model's NAO, relative to model areas of persistent surface forcing. This indicates that the link between sea-ice and NAO could be exploited as a potential skill-source for multi-year prediction by addressing the key problem of initializing the phase of the NAO/ AO (Arctic Oscillation).

Keyword NAO $\cdot$ Arctic sea-ice $\cdot$ Meridional thermal gradient

\section{Introduction}

Natural variations of the sea level pressure (MSL) dominate the northern hemisphere climate variability. Over the Atlantic and Europe, the North Atlantic Oscillation (NAO) or the overlapping paradigm of the Arctic oscillation (AO, Aarten et al. 2001) strongly impact weather and climate conditions (Hurrell et al. 2003). In that sense, the NAO mode is considered more physically relevant and robust for the Northern Hemisphere variability than the AO (Ambaum et al. 2001). Reasons for NAO variability are not well understood yet; however, interactions with other teleconnection patterns have been explored and emphasized (Huang et al. 1998; Semenov et al. 2008; Park and Dusek 2013). Arctic sea ice conditions have been investigated in relation to NAO and large-scale circulation in observational and modelling studies.

In observational studies the Arctic sea ice extent has been linked through statistical connections (Herman and Johnson 1978; Alexander et al. 2004) to large-scale circulation patterns in mid and even subtropical latitudes. These studies have shown that the full atmospheric response to sea-ice extent variability could not be explained by local thermodynamics, suggesting that dynamical processes are 
of primary importance. Recently, a large number of studies linked the reduction of sea ice extent to observed negative trends in the NAO-index and to winter weather extremes in mid-latitudes (Petoukhov and Semenov 2010; Overland and Wang 2010; Yang and Christensen 2012; Francis and Vavrus 2012; Hopsch et al. 2012; Köenigk et al. 2015). The relatively short time series of reliable sea ice data together with a climate in transition makes the interpretation of possible linkages between sea ice reduction and mid-latitude climate extremes difficult.

Earlier modelling experiments (Parkinson et al. 2001; Singarayer et al. 2006; Semmler et al. 2012) indicate that less ice in the Arctic is connected to a warming over high latitudes in the lower troposphere, to a significant decrease in the intensity of the westerlies and of the storms poleward of $45^{\circ} \mathrm{N}$ and to a general increase in the westerlies in tropical and subtropical regions. The opposite impacts have been obtained when the sea-ice cover was more extensive (Murray and Simmonds 1995; Honda et al. 1999; Budikova 2009). The reduction in the mid-latitude westerly flow under reduced sea-ice conditions has been related to a reduction in the meridional temperature gradient between the high and low latitudes and to a concurrent increase in the geopotential height at high latitudes mid-troposphere. This was shown to result in a decline in the surface temperature and a barotropic geopotential low at mid-latitudes (Royer et al. 1990; Deser and Teng 2008). However, controversy exists regarding the amplitude and robustness of the signal (Screen 2014; Barnes 2013). Previously, mass adjustment at high latitudes under the removal of sea ice cover and associated mid-latitudes cooling, was shown (Royer et al. 1990; Raymo et al. 1990) to affect particularly the wave-number four pattern. This adjustment showed mid-tropospheric geopotential height increases over the Atlantic (Iceland and Norwegian Sea) and the Eurasian (Siberia and West Bering Sea) sectors and decreases over the East Pacific, Sea of Japan, Black Sea and West Atlantic areas.

On regional scale the winter Arctic sea ice cover variability shows out-of-phase fluctuations between the western and eastern sectors of the Atlantic (Labrador and Greenland-Barents seas) and between Bering and Okhotsk seas in the Pacific in observational data (Deser et al. 2000). In modelling studies, a link has been indicated between the leading pattern of Arctic sea ice cover and the NAO variability, with impacts on the Atlantic basin and the European continent during winter (Alexander et al. 2004; Dethloff et al. 2006; Gerdes 2006; Deser et al. 2007). Alexander et al. (2004) have shown, simulating the winters of 1982/1983 and 1995/1996 with an ensemble of AGCM model experiments, that the intra-annual large-scale atmospheric response to sea ice cover anomalies over the Atlantic and Pacific sub-polar seas is shallow and resembles the internal mode of atmospheric variability of the North Atlantic/Arctic Oscillation (NAO/AO) such that increased/ reduced ice conditions in West/East Greenland were favouring, the same winter, a negative phase, in opposite to observations. They concluded that nonlinear interactions between Arctic sea ice and the overlying atmosphere may have an important role in governing the phases of the NAO. Also it was pointed out that these nonlinearities act differently in the Atlantic and the Pacific (Alexander et al. 2004; Magnusdottir et al. 2004; Deser et al. 2004) and lead to a positive feedback mechanism on the atmospheric circulation in the Pacific and a negative feedback in the Atlantic. Large feedbacks on the atmosphere were shown to be conditioned, for the North Pacific (Liu and Alexander 2007), by the existence of out of phase sea ice extents in the Sea of Okhotsk and the Bering Sea.

Until recently, the seasonal prediction skill of the NAO resulting from model predictions was low, although progress has been reported in analysing mechanisms of its high frequency variability (Benedict et al. 2004; Strong and Magnusdottir 2008). However, Scaife et al. (2014) showed a significantly improved NAO prediction skill at seasonal time scale using the newest generation of models, increased resolution and large ensembles. Regarding the interannual to decadal prediction, the NAO sources of variability were studied mainly in relation with other modes of variability (Smith et al. 2014). Also its recent trends were analysed in relation with sea-ice loss over the last decades (Bader et al. 2011; Cohen et al. 2014). There are far less attempts to assess causal links with the NAO at interannual time scales, although already Slonosky et al. (1997) showed that sea ice anomalies over the Greenland Sea lead pressure anomalies by 1 year with positive correlation. For long term initialised predictions it is however important to assess the forcing and areas leading the interannual NAO variability. Understanding the mechanisms of this leading would allow improving the NAO phase initialisation in model's space and the first-years' prediction skill. Analysing mechanisms involved in leading NAO yearly variability is the main aim of this work.

In Sect. 2 we present the data and methods. We analyse nonlinear leading processes related to NAO over the Arctic in Sect. 3 and in Sect. 4, a physical mechanism of this leading is discussed. In Sect. 5 we analyse the robustness of this mechanism under transient climate. In order to extract predictive information on NAO at annual range, the model's ability to reproduce observed leading mechanisms is analysed. Conclusions are presented in Sect. 6 .

\subsection{Data and methods}

The analysis focuses on two distinct time slices: one covering the period from 1960 to 2001 (time interval referred as 
"slice1"), and another covering recent climate: 1980-2014 (time interval referred as "slice2"), for the December-January-February (DJF) season. Analyses of slice1 are based on ERA40-reanalysis data (Uppala et al. 2005) while slice2analyses are based on Era-Interim-reanalysis data (Dee et al. 2011). For the analysis of sea-ice parameters (Kållberg et al. 2004), we will in addition focus on the period from 1978 to 2001 as sub-slice of slice1 ("slice1ci") to cover the period of satellite observations. The Global Climate Model (GCM) used here is EC-Earth version 2.3 (Hazeleger et al. 2012; Sterl et al. 2012). A detailed description of the representation of Arctic climate in this model version is presented in Koenigk et al. (2013). The atmospheric component of EC-Earth is the Integrated Forecast System (IFS) of the European Centre for Medium Range Weather Forecasts (ECMWF) (Molteni et al. 2011). The version used here is based on cycle $31 \mathrm{r} 1$, at a T159 resolution with 91 vertical levels. The ocean component is based on the Nucleus for European Modelling of the Ocean (NEMO) version 2.0 and includes the sea ice model LIM2 (Madec et al. 1998; Bouillon et al. 2009). The model analysis is done on the time slice 1980-2005 ("slice2m") from an atmospheric only run and from a coupled run with the EC-Earth model, both using the CMIP5 external forcing. The atmospheric only run is based on the AMIPII (the second set of Atmosphere Model Intercomparison Project simulations) and uses predefined sea surface temperature (SST) and sea-ice concentration (CI) from ERA-interim data as lower boundary conditions.

Our goal is to identify high latitudes processes that lead the NAO index. The first step is to identify variables and Arctic regions, which show a nonlinear linkage to the NAO phase on interannual time scales. Then we analyse only leading relations and areas-as potential sources triggering transition from one NAO phase to the other.

The NAO index is defined using mean sea level pressure anomalies differences between the Azores and Iceland. The same definition is used for model's NAO, being consistent with model's variability (as shown in Supplementary figure S1).

For a given variable, we define it as being nonlinear as a function of the NAO phase (or NAO-nonlinear) as follows: first we stratify the anomaly data into two sub-ensembles of years corresponding to positive/negative NAO index above/below a given threshold of the standard deviation (stdev) of the NAO index. Then we compute the average (composites) of the variable's anomalies over the two subensembles. The anomalies are considered with respect to the climatological means of the respective time slices. The nonlinearity of a variable as a function of the NAO index is simplified in the sense that a positive/negative product of the two composite anomalies (i.e., averaged over the two sub-ensembles of the same variable stratified upon
NAO phases) is considered, pointwise, a nonlinear/linear relation.

This simplification focuses on the phase difference (inhomogeneous nonlinearity) with the NAO. As it assumes that the two ensemble average anomalies have opposite signs in a linear response (pointwise), this is a weak (phase average) nonlinearity condition, aiming to identify linkages between oscillatory processes. A measure of this nonlinearity can be considered as a function of the threshold: at a higher threshold (stdev), only higher phase differences will be filtered as being nonlinear, according to the definition chosen. This analysis is conducted for the following DJF anomalies: cloud fraction (CFR), cloud total (TF) and clear sky (CSF) forcing defined as net fluxes at the top of the atmosphere (TOA). Furthermore, surface temperature (TS) and mean sea level pressure (MSL) are analysed.

\section{Nonlinear analysis}

\subsection{Nonlinear NAO related areas}

Figure 1 shows the composites of TS, MSL, CFR and $\mathrm{TF}$ for positive and negative NAO-index exceeding $+/-1$ stdev. For all four variables, a high degree of linearity occurs. The spatial correlations between the positive and negative NAO-phase composites of these variables (Table 1) show a high negative correlation. Increasing the threshold towards $1.5 \mathrm{stdev}$ leads, as expected, to a reduced spatial correlation between the composites and point to the areas of main nonlinearity. These areas are shown in Fig. 2 for thresholds of 1.5 and 1 stdev. We note that the TS-NAO nonlinearity primarily co-varies with processes involving cloud feedback and radiation: the spatial distribution of the areas with TS-NAO nonlinearity corresponds relatively well with either the nonlinear TF or CSF areas, pointing to these as nonlinearity sources for TS over the Arctic and high latitudes.

Physical mechanisms for common nonlinear areas of CSF and TS in Fig. 2 are mainly related to low level dynamical-advective processes involved in sea ice formation and transport and snow cover variability. Additionally, permafrost can delay the Planck feedback over land areas and be associated with nonlinearity seen in the long wave CSF radiative forcing (not shown). Areas, where TS nonlinearity overlaps the $\mathrm{TF}$ nonlinearity regions point to a contribution from cloud variability (Wang and Key 2003).

Figure $2 \mathrm{c}$ shows three main areas of TS-NAO nonlinearity for both thresholds. The first two are joined onto an Arctic belt connecting Laptev-East Siberian seas-Far East Asia land-Okhotsk Sea to the North East GreenlandLabrador-Davies Strait. They are linked to the Transpolar Drift (TPD) strength, Laptev sea ice formation and ice 
(a) TS
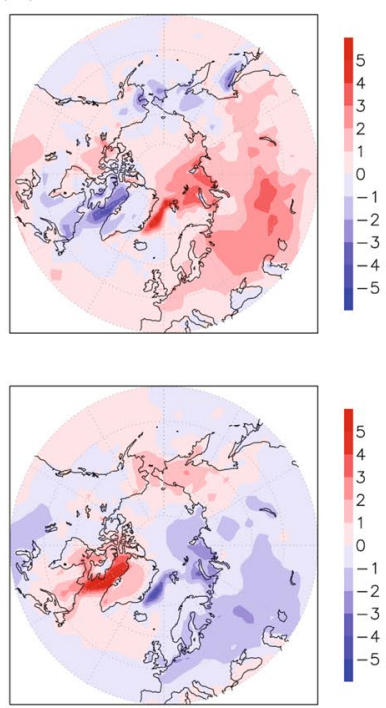

(b) MSL
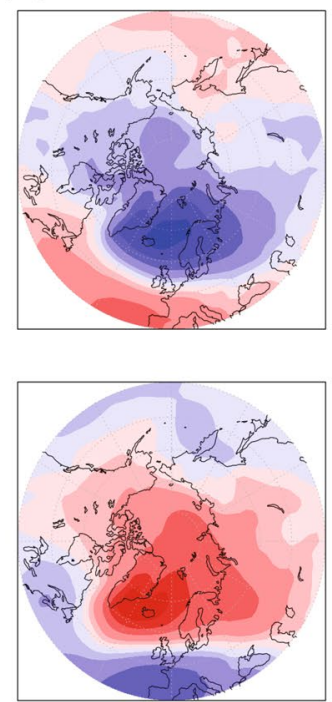

(c) Cloud Fraction
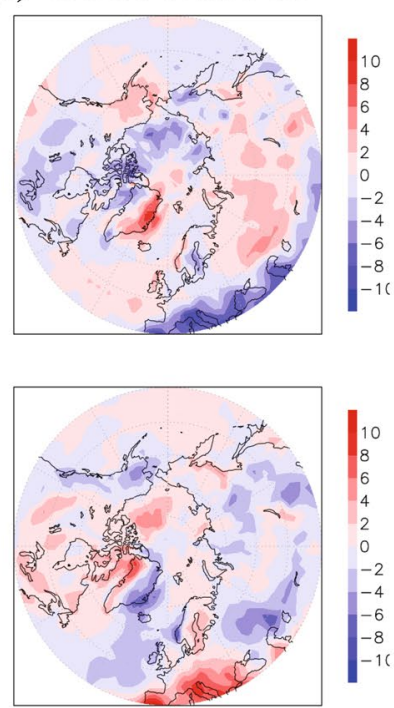

(d) Cloud Forcing
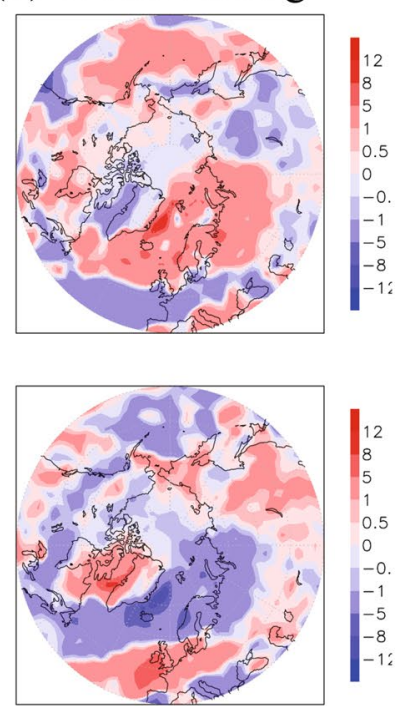

Fig. 1 Composite anomalies over years with: $\mid N A O$ index $\mid>(1$ standard deviation $)$, for: a surface temperature [K], b mean sea level pressure $[\mathrm{mb}], \mathbf{c}$ cloud fraction [\%] and $\mathbf{d}$ cloud forcing [1e-4 W/m²], for NAO+composites (top) and NAO-composites (bottom), ERA40 DJF slice1

Table 1 Spatial correlations over $\left[50^{\circ} \mathrm{N}, 90^{\circ} \mathrm{N}\right]$ between the composites over years with NAO+and NAO-exceeding: 1 standard deviation and 1.5 standard deviation, from ERA40 DJF slice1

\begin{tabular}{llll}
\hline Surface temperature & Low clouds & Mid-level clouds & High clouds \\
\hline$-0.82 /-0.55$ & $-0.72 /-0.49$ & $-0.64 /-0.49$ & $-0.68 /-0.38$ \\
\hline msl. pressure & lw cloud-forcing & sw cloud-forcing & Total cloud-forcing \\
\hline$-0.87 /-0.81$ & $-0.79 /-0.55$ & $-0.70 /-0.45$ & $-0.80 /-0.54$ \\
\hline
\end{tabular}

transport through the Fram Strait and Canadian Archipelago as they show nonlinearities in both TF and CSF. A third source of TS nonlinearity is linked to ice variability at the Barents sea. On the other side, we find two interesting nonlinear areas that are not found in TS: the extension of the Gulf Stream and the Norwegian current (nonlinear in CSF) with a mid-latitude track over Europe (nonlinear in $\mathrm{TF}$, due to humidity advection and clouds formation), and then the North Pacific-Bering Sea (nonlinear in CSF, Fig. S2). These indicate that the main out-of-NAO phase physical process is the advective evaporation over the Northern oceans and cloud formation reflected in the short wave CSF and TF. Their composites ratio TF/CSF (Fig. S3) shows they enforce each other over Northern oceans (with TF dominating), enhancing their feedback on surface. In opposite, the CSF nonlinearity dominates over high latitudes land, Arctic seas and the Central Arctic of higher ice variability (Cavalieri and Parkinson 2012) pointing to sea-ice and permafrost variability as main nonlinearity sources.

MSL shows in Fig. 2d a main, rather hemispheric nonlinearity at mid-latitudes, apparently initiated and persistent over the western side of northern oceans Labrador and Okhotsk seas (as the nonlinearity here is present at both 1.5 (also in TS, CSF and TF) and at 1 stdev), and propagating Eastwards and over northern continents. Lower nonlinearity, only at 1 stdev (smaller phase difference) is seen over Northern Europe and Far-East Asia (north-east Siberia). This, found also for TS (Fig. 2c) at 1.5 and 1 stdev, appears linked to persistent surface forcing by soil inertia and snow cover, as also suggested in other studies (Cohen and Barlow 2005; Allen and Zender $2011 \mathrm{a}, \mathrm{b})$ to represent a seasonal link between winter pressure and previous autumn surface forcing.

The links between TS and MSL main nonlinearities are supported by previous studies. Honda et al. (1996) showed that anomalous sea-ice cover and surface heat flux over the Sea of Okhotsk area excite thermally a stationary Rossby wavetrain with a through over eastern Siberia and the Sea of Okhotsk and North Pacific and a ridge over Alaska and the western Arctic Ocean. On the Atlantic side, previous studies Magnusdottir et al. (2004), Alexander et al. (2004), Kvamstö et al. (2004), Koenigk et al. (2006) already indicated the importance of sea ice 
Fig. 2 Areas of nonlinear (see text) relation to NAO for composites over years exceeding: 1.5 NAO standard deviation (grey shading) and $1 \mathrm{NAO}$ standard deviation (blue line) for: a cloud forcing, $\mathbf{b}$ clear sky forcing, $\mathbf{c}$ surface temperature and $\mathbf{d}$ mean sea level pressure (zoom-out), from ERA40 DJF, slice 1
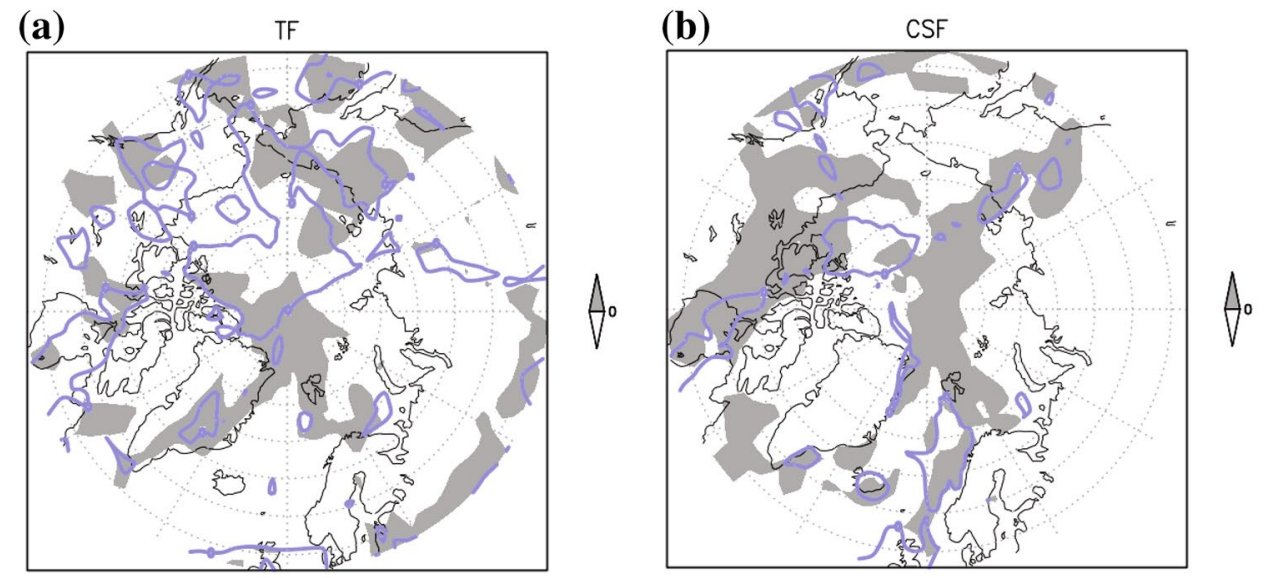

(c)

TS

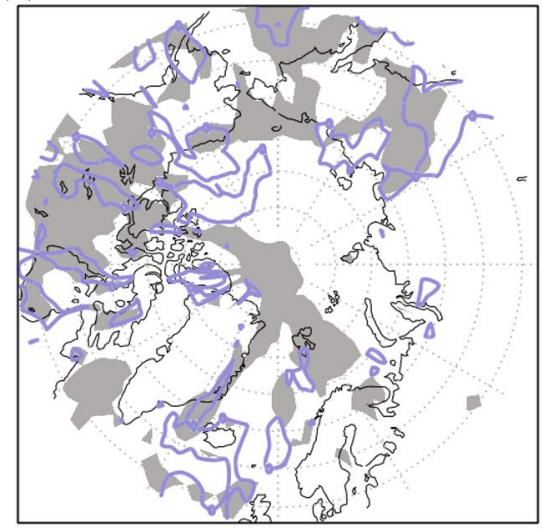

(d)

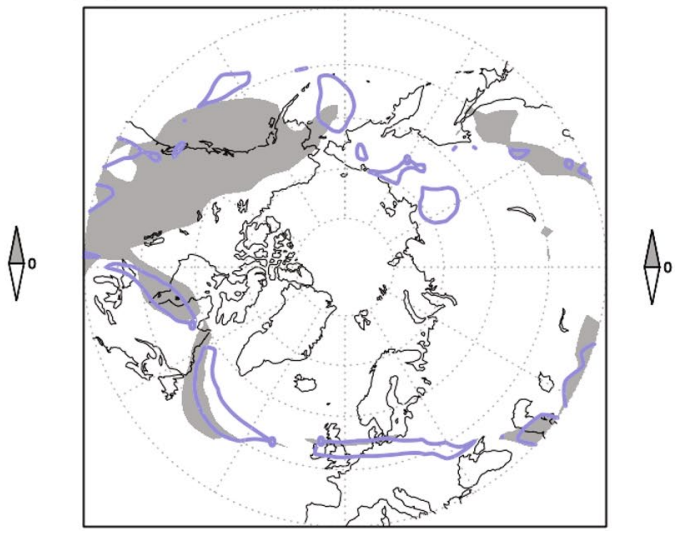

variations in the Labrador Sea for the large scale atmospheric circulation over the North Atlantic.

This composite analysis identifies broader-area processes potentially linked to phase changes of the NAO. The diabatic and surface forcing over these areas fulfils a weak (average) condition of phase-shift relative to NAO. The composites threshold provides a measure of the processes time-lag. However, it does not show yearly leading relations, which are further analysed below.

\subsection{Leading the NAO in reanalysis data}

To retrieve yearly leading areas we consider full time series. We compute pointwise time correlations over the slice 1 between the NAO index and the same variables as (a) TF leads NAOi $1 \mathrm{y}$

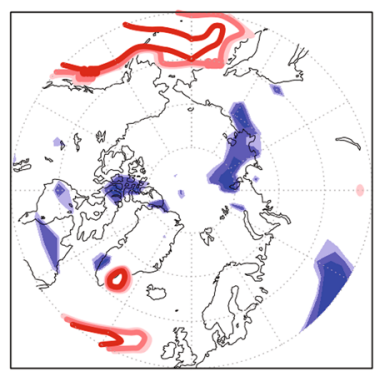

(b) CSF leads NAOi 1 y

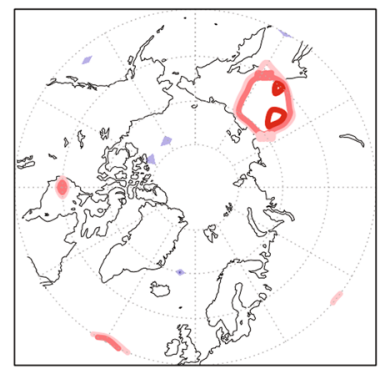

Fig. 3 Areas with significant correlations where the NAO is led with 1 year by the: a cloud forcing, $\mathbf{b}$ clear-sky forcing, $\mathbf{c}$ sea level pressure (MSL) anomalies, from ERA40 DJF, slice1; d same for MSL leading NAO by 2 years. Red/blue colours represent positive/negative corre- (c) MSL leads NAOi 1y

(d) MSL leads NAOi 2 y
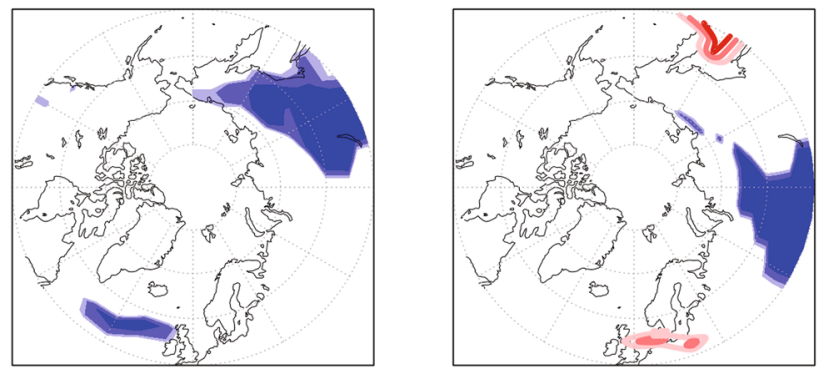

lations. Darker/middle/light blue shading (for negative) and red line (for positive) show areas at 0.99, 0.95 and 0.80 level of statistical significance 
(a) TF leads MSL 1y

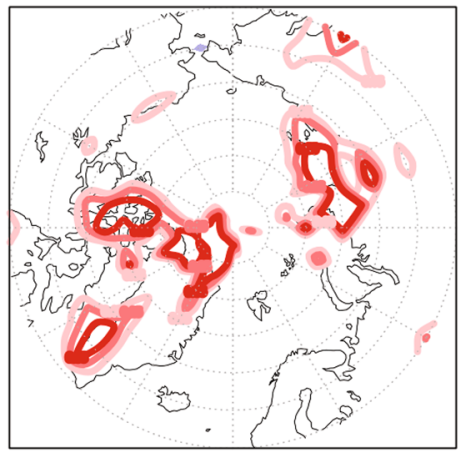

(d) CI leads MSL 1y

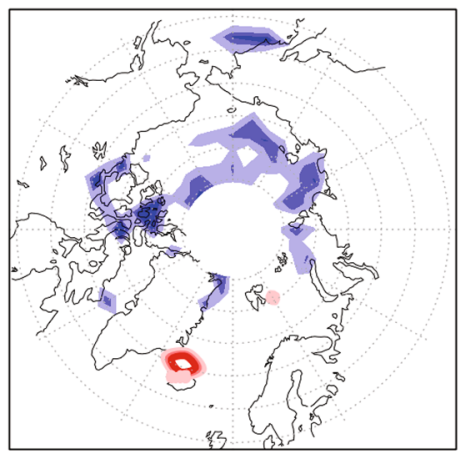

(g) TS leads NAOi 1y

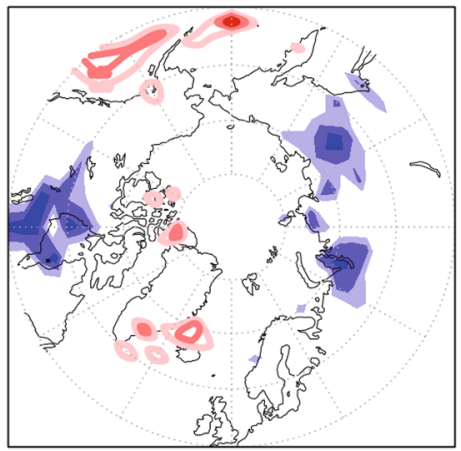

(b) TF, MSL zero lag

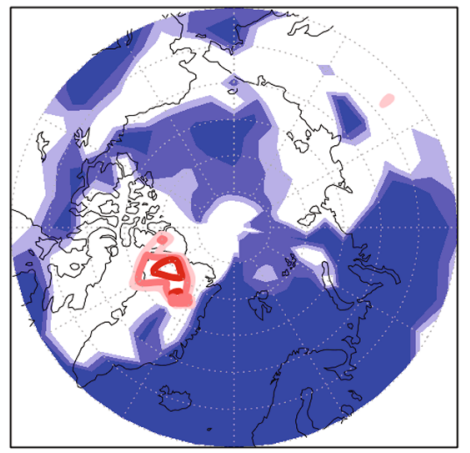

(e) CI leads NAOi 1y

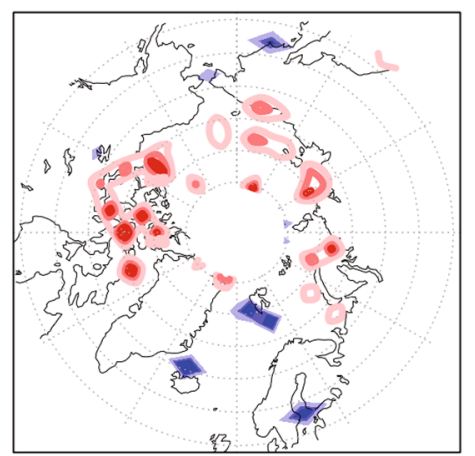

(h) TS leads MSL 1y

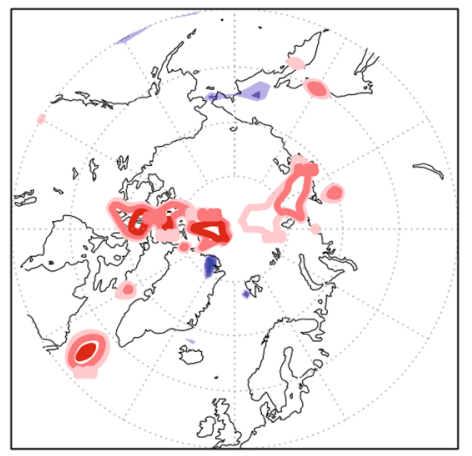

(c) TF Dec. leads CI Jan.

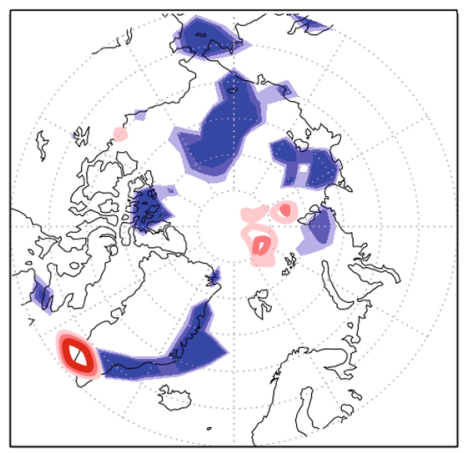

(f) CI leads NAOi 2y

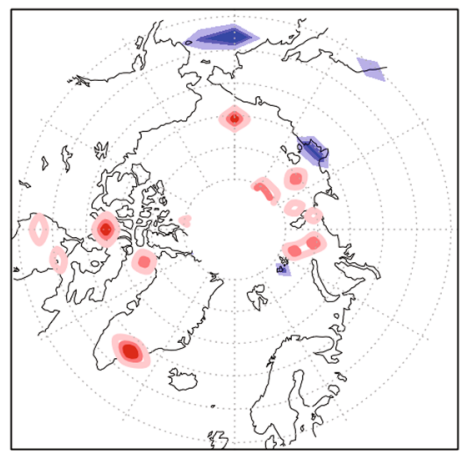

(i) TS leads MSL 2y

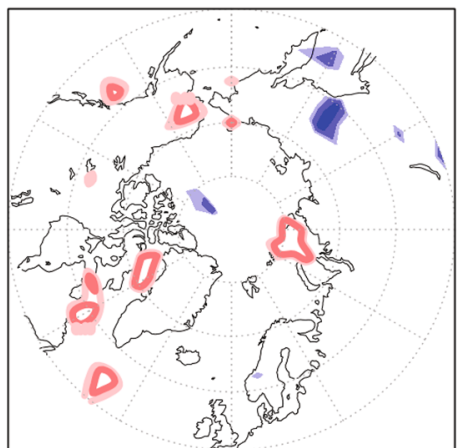

Fig. 4 Areas of significant correlation where: a TF leads MSL by 1 year; $\mathbf{b}$ TF and MSL are related at zero lag; $\mathbf{c}$ December TF leads the following January CI; d CI leads MSL by 1 year; e CI leads the NAO index by 1 year; $\mathbf{f}$ CI leads by 2 years the NAO index; $g$ TS leads by 1 year the NAO index; $\mathbf{h}$ TS leads by 1 year the MSL; $\mathbf{i}$ TS

before, over the Arctic and high latitudes. Leading correlations are computed for lags of $+/-3$ years and are shown in Figs. 3 and 4.

Figure 3 shows the areas with statistically significant correlations (we use here one-tailed test probability p-levels) where TF, CSF and MSL lead the NAO by 1 or 2 years. For TF, areas where this is leading the NAO index by 1 year show negative correlations over the Laptev Sea-North Okhotsk sea and over the Canadian Archipelago-Hudson leads by 2 years the MSL. For correlations with sea ice concentration (CI) the time slice is 1976-2001 otherwise is slice1, ERA40 DJF. Colours are as in Fig. 3. (We neglect correlations over the Central Arctic due to lower statistical significance of observed CI variability)

Bay-West of Labrador sea. Positive correlations of this leading occur over the North-East Atlantic and Pacific. CSF leads NAO by 1 year over the North Hudson Bay and over eastern Siberia, with positive CSF anomaly (linked to colder surface) leading NAO+.

The MSL leading NAO anomalies indicate an eastward advancement of the low-pressure system from Central (2 years leading, Fig. 3d) to East Asia (1 year leading, Fig. 3c). These patterns fit well with the climatological 
pattern of Eurasia snow water content over 1966-2000 (Bulygina et al. 2011), suggesting this persistent leading may rely on soil memory and surface exchange over these areas. We note that the nonlinearity MSL-NAO area over the United States (Fig. 2d) does not appear as a NAO leading area in Fig. 3c, d indicating that its variability is lagging the NAO. In opposite, the MSL belt of nonlinearity over the Central North Atlantic (found at threshold 1.5 and 1 stdev in Fig. 2d), is a leading area in Fig. 3c, d and indicates an Eastwards wave propagation (Fig. 2d, only present at $1 \mathrm{stdev}$ over North-East Atlantic and over land) linked to the Labrador area and forced by diabatic processes (CFS, TF lead also over this area-Fig. 3a, b), that persist (CSF, Fig. S2). The remote importance of the Labrador area on the atmospheric intra-seasonal circulation was noticed also in other studies (e.g. Petrie et al. 2015), the analysis here indicating its extended potential in leading remote process at yearly time-scale.

These leading regions correspond to the broader ones found to be systematically (in average) out-of-phase relative to NAO in the nonlinear composite analysis.

Figure 4a shows for the slice1 the statistically significant correlation areas between TF and MSL, with TF leading MSL by 1 year. Enhanced surface cooling by negative cloud forcing over the Laptev and Okhotsk seas and over the Canadian Archipelago/northern Greenland and the Labrador Sea, lead a surface pressure drop over these areas in the following winter, in agreement with Fig. 3a and the MSL pattern in Fig. 1b. In all other areas of the Arctic domain, TF is significantly negatively correlated with MSL at a zero time-lag (Fig. 4b) as also emphasised in previous work (Park and Leovy 2000). For CI, we consider correlations over 1978-2001 ("slice1ci", sub-set of "slice 1"), where time-homogeneous CI data are available in ERA40. This does not affect the results: the leading correlations and patterns remain largely unchanged among the other variables over slice1ci. Figure $4 \mathrm{~d}$ shows, as for TF, that enhanced surface cooling from positive anomalies of CI over the northern Kara Sea and a track connecting the Laptev-East Siberian seas to the Canadian Archipelago leads a MSL drop in the following year. Over the same areas, positive $\mathrm{CI}$ anomalies also lead the NAO+by 1 year (Fig. 4e). This points to a feedback CI-MSL in which MSL contributes to CI variability the same year while CI persistent anomalies lead the MSL change in the following year (Fig. 4d). Also, CI formation and persistence appears reinforced by TF: TF leads CI formation the same year as seen in Fig. 4c, over areas where both lead a same MSL change the following year.

Two other significant correlation areas north and south of the Odden area $\left[70^{\circ} \mathrm{N}-75^{\circ} \mathrm{N}, 15^{\circ} \mathrm{W}-5^{\circ} \mathrm{E}\right.$, Jeffrey and Hung (2008)] indicate that less ice cover at those locations leads NAO+ and MSL decreases. This state leading the NAO+ (characterised by ice melt at the Odden borders) indicates a lower transport through the Fram Straitsouth Iceland (or a low TPD phase): as shown by Rogers and Hung (2008) using NCEP-NCAR reanalysis data, ice anomalies in the Odden area are in phase with the east Greenland current south of $75^{\circ} \mathrm{N}$ to Iceland.

TS leading MSL areas (Fig. 4h) are coherent with CI leading areas in Fig. 4d over iced areas, again with cold surface leading pressure drop in the following winter, over the Arctic along two main branches: over the Canadian Archipelago-Labrador and over the Laptev-East-SiberiaOkhotsk seas. Earlier signal leading a MSL drop by 2 years is a colder Labrador sea and Flemish Cap (Fig. 4i) and iced Kara Sea with cold advection over land linked to the cyclonic vorticity ahead seen in Fig. 3d. Of the TS-MSL links, the main relevant ones in leading $\mathrm{NAO}+$ are the TS cold anomalies 1 year ahead persisting over the West side of both Northern oceans: at Hudson Bay-West Labrador and over Far-East Asia land and West Okhotsk Sea (Fig. 4g), areas that bridge between Central Arctic and high latitudes oceans and land (Figs. 2, 3, 4e, h). These two areas are coupled with a warmer South-East Greenland respectively East-Pacific (Fig. 4g). These surface anomaly dipoles are associated (un-lagged), in simple models of a baroclinic environment, to a high/low pressure West/East sides of the Davies Strait and of the Far-East Asia-Okhotsk Sea as a characteristic of the leading, discussed further.

Previous studies have analysed the relation between early autumn Siberian snow cover and the NAO winter index. Figure $4 \mathrm{~g}$ shows that the surface cold anomaly over the East Siberian high-latitudes land (east of $120^{\circ} \mathrm{E}, 65^{\circ} \mathrm{N}$, nonlinear in Fig. 2d) leads NAO+by 1 year, whereas no leading signal is found from central Siberia in Fig. $4 \mathrm{~g}-\mathrm{i}$. It follows that the mechanism proposed in previous studies with cold surface over central Siberia enhancing the wave propagation and diminishing the polar vortex strength (Cohen and Entekhabi 1999; Bojariu and Gimeno 2003) might be limited at seasonal time-scale. In our case the Far East-Siberia's TS cold anomaly is reflected, if de-composed, in the long-wave CSF (Fig. 3a) and is coherent with Arctic cold advection over the Laptev-Okhotsk seas and sea-ice formation leading NAO+ (Fig. 4e).

\section{The leading mechanism}

\subsection{Sea-ice driving MSL}

We further investigate the link emphasised in Sect. 3 between CI and the following year MSL (with cold anomaly leading a pressure drop), in relation with the NAO maximal phase. We use a composite analysis of the 3 years before a positive NAO index exceeding 1 stdev (Ym3+, 
(a) $\Delta_{\mathrm{t}} \mathrm{CI}(\mathrm{t})$
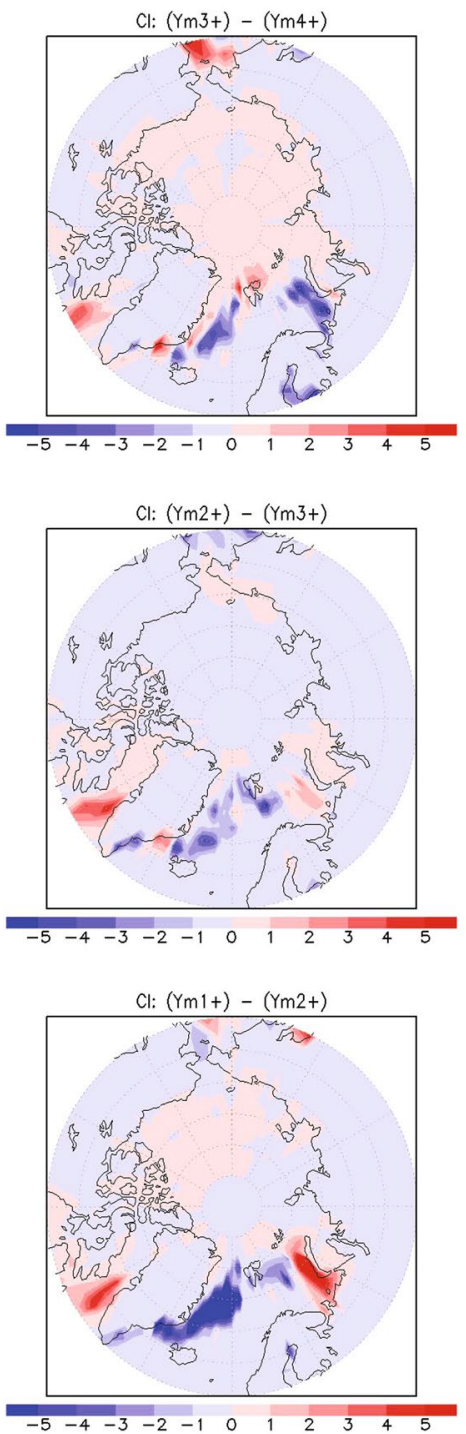

(b) $\Delta_{\mathrm{t}} \mathrm{TS}(\mathrm{t})$
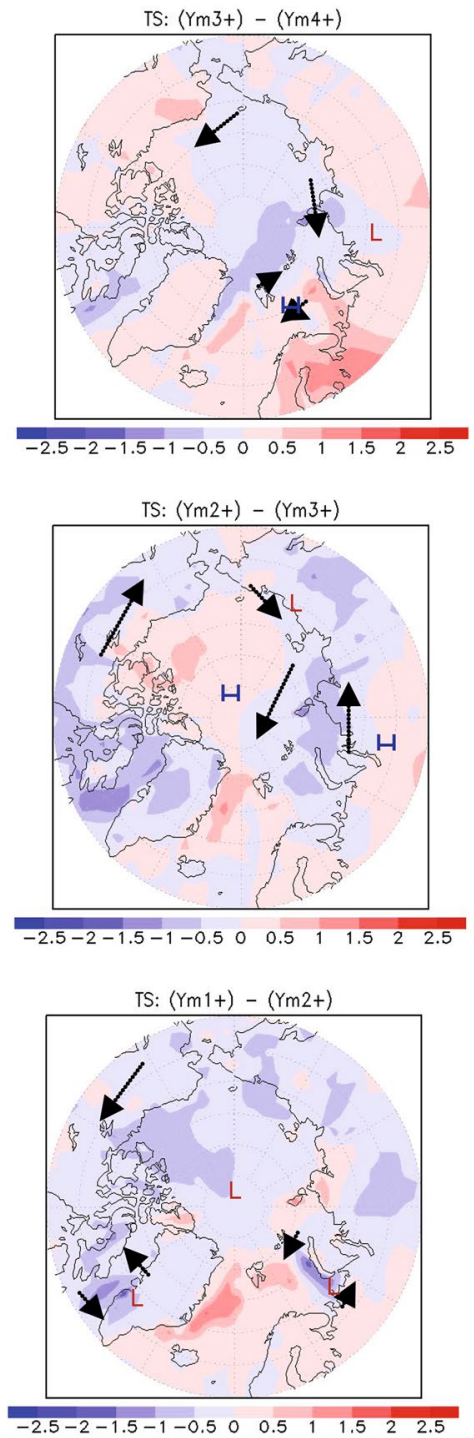

(c) $\Delta_{\mathrm{t}} \mathrm{MSL}(\mathrm{t}+1 \mathrm{y})$
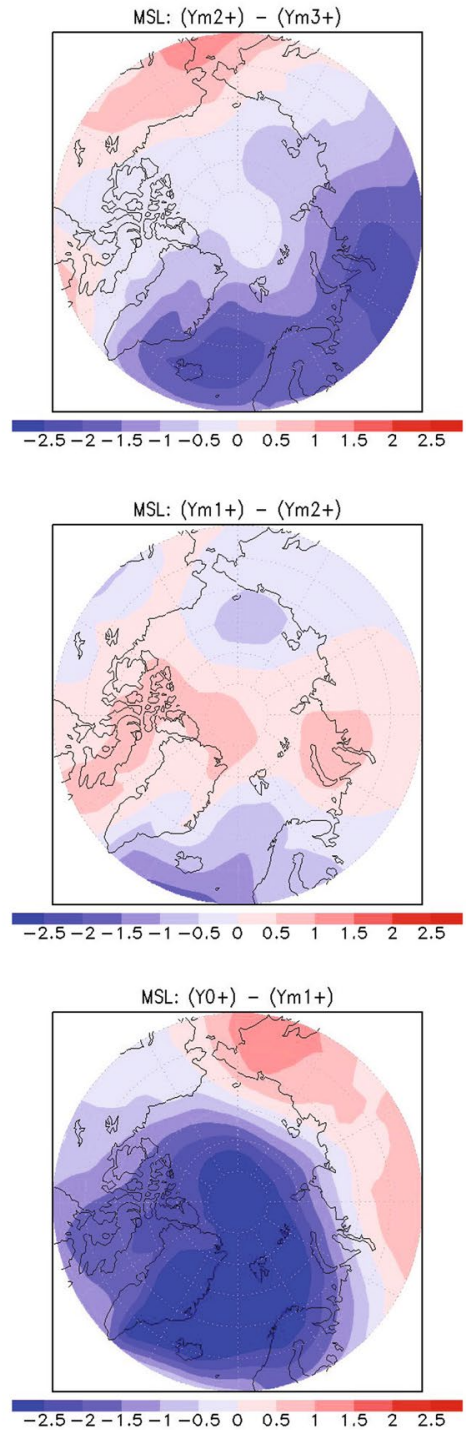

Fig. 5 Composite yearly tendencies from ERA40 DJF, slice1, at times: Ym3+ (top), Ym2+ (middle) and Ym1+ (bottom), for: a CI [ CI, (\%)], and b TS [. TS, (K)]; c composite yearly tendencies of MSL

$\mathrm{Ym} 2+$ and $\mathrm{Ym} 1+)$ in slice1. We analyse in Fig. 5 the relation between yearly tendencies of CI and TS, and the MSL tendency in the following year. The tendencies are averaged over the the three leading times composites.

The tendency fields at $\mathrm{Ym} 1+$ (difference at $\mathrm{Ym} 1+$ minus $\mathrm{Ym} 2+)$ and at $\mathrm{Ym} 2+$ capture the patterns of significant NAO leading correlations in Fig. 3, such as the low pressure tendency at $\mathrm{Ym} 2+$ located in north-central Russia $\left(80^{\circ} \mathrm{E}\right)$ and at Ym1+located in Far-eastern Siberia (Fig. 5c), as well as the CI patterns leading NAO+at $\mathrm{Ym} 1+$ in Fig. $4 \mathrm{e}$ (with positive anomaly tendency at $\mathrm{Ym} 1+$ over the eastern Barents/Laptev seas, northern Okhotsk Sea and northern
[ MSL, (hPa)], valid 1 year later compared to tendencies in $\mathbf{a}$ and $\mathbf{b}$. Arrows on the TS plots schematize thermal wind anomalies above the boundary layer induced by CI

Beaufort Gyre/Canadian Archipelago/Labrador Sea and with negative anomaly bordering the Odden area).

We note three systematic features in this analysis. A first feature (1) is that the average TS tendency at any year $\mathrm{Y}$ over the Arctic (Fig. 5b) is directly related to the CI tendency at the same year (Fig. 5a): negative CI mean anomaly matches positive TS mean anomaly. A second one (2) is that systematically, the MSL tendency (Fig. 5c) is dominated by the pressure adjustment to the large-scale thermal wind persistent forcing from 1 year before. The thermal wind forcing is generated by the meridional TS gradient (separating colder air and lower pressure to its left side and 
warmer air and higher pressure to its right) and represents a quasi-steady forcing over Arctic areas of persistent surface anomalies. This relation is seen for all three composites leading the NAO, and keeps valid for ensembles defined at thresholds of $0.75,1.5$, and 2 standard deviations of the NAO index (not shown).

The adjusted pressure would in turn drive new CI anomalies, and the MSL-CI feedback suggested by the composite analysis in Fig. 5 can be schematized through a coupled system:

$$
\begin{aligned}
& (\mathrm{ps})_{Y}^{\mathrm{adj}}=\mathrm{f}\left(\frac{\partial \mathrm{ci}}{\partial y}\right)_{Y-1} \\
& \left(\frac{\partial \mathrm{ci}}{\partial t}\right)_{\mathrm{dyn}}=\mathrm{g}(\mathrm{ps})
\end{aligned}
$$

with $p s$ the surface pressure and $f, g$ functions of respectively the meridional gradient of CI and of the surface pressure. The first relation involves the pressure anomaly adjustment tendency over 1 year $\left(\mathrm{ps}_{Y}^{\mathrm{adj}}\right)$ in response to the thermal wind forced by quasi-steady meridional CI gradient tendency the year before (and by TS, conform (1) and Fig. 5a, b). The relation holds over areas of persistent forcing. The second relation involves the CI yearly tendency due to the atmospheric dynamics (surface pressure and related geostrophic CI transport and temperature advection). We will compute the yearly gradients (shown in Fig. 5) and analyse their persistence in Sect. 4b, for both NAO phases.

A third systematic feature in Fig. 5 (3) concerns the year preceding the maximal NAO phase. It consists in the development of a high pressure anomaly tendency at $\mathrm{Ym} 1+$ (Fig. 5c, $2^{\text {nd }}$ row) over the Central Arctic, with centres over the NW Greenland-West Baffin Bay and over the KaraLaptev seas. This feature is also robust across all thresholds and for both slice1 and slice2. This anomaly development is coherent with (2), driven by a large CI reduction tendency over the Central-Western Arctic 1 year before (at $\mathrm{Ym} 2+$ ) and by associated TS meridional gradients (Fig. 5a, b, $2^{\text {nd }}$ row).

The high pressure anomaly at $\mathrm{Ym} 1+$ (the opposite holds at Ym1-, Fig. S4) is a key feature of the 1 year leading NAO mechanism. Its southward branches bring cold advection respectively over the Hudson Bay-Labrador Sea (with a secondary branch over the North Barents-Greenland seas, Fig. $5 \mathrm{c}, 2^{\text {nd }}$ row) and over the Laptev-East Siberian Sea down to the Okhotsk Sea. Hence over both North-West Atlantic and North-West Pacific evaporative cooling takes place and broad, ocean-wide, low pressure systems develop over high latitudes oceans with strong latent heat advection over mid-latitudes land. These features are well seen in the TS tendency at $\mathrm{Ym} 1+$ (Fig. 5b, $3^{\text {rd }}$ row) and agree with the patterns leading NAO found in Fig. $4 \mathrm{~g}-\mathrm{i}$. They create a quasi-annular, persistent forcing with cold/warm anomaly (and high/low pressure anomaly) over Arctic/mid-latitudes at $\mathrm{Ym} 1+$, that triggers positive vorticity the following year over the Central Arctic, i.e. the positive phase of the AO/ NAO (Fig. 5c, $3^{\text {rd }}$ row).

This feature is in agreement with what was observed during 2007 (preceding a strong NAO+the following winter) when a switch towards an anticyclonic Arctic was noticed, while the entire year 2009 (preceding a strong AO- the following winter) was characterized by an unusual change towards an extended cyclonic Arctic ( Timmermans et al. 2011).

Finally we note that the slow, yearly adjustment tendency of the pressure $\mathrm{ps}_{Y}^{\text {adj }}$ in response to the forcing by persistent surface TS anomalies, appears equivalent barotropic: the upper levels thermal wind leads a slow forcing (cyclonic over cold surface anomaly) on the column geopotential height and surface pressure (damping over cold anomaly). An idealised simulation performed using a simplified-aqua-planet version of the Ec-Earth model showed the same response: a pressure drop over a persistent cold SST anomaly, and the annularity of the response to an annular forcing (Fig. S5). The thermal wind forcing is maintained through persistence of surface fluxes column anomalies-associated to areas of persistent thermal gradients. Rinke et al. (2006) estimated Arctic CI impact on surface fluxes as a linear function of CI such that a $0.1-0.5 \mathrm{CI}$ anomaly may lead to an increase of fluxes by up to $15-75 \%$. These significant anomalies would then create a quasisteady vertical gradient of vorticity advection that leads a slow pressure tendency (decay for positive vorticity) downstream at lower levels. Only a slow phase advancement is expected due to the quasi-stationarity of the forcing but these deserve further analysis in a future work.

\subsection{The leading role of coastal meridional gradients}

We quantify here: the role of the CI meridional gradients in leading NAO (discussed in Fig. 5), and their persistence. The use of CI gradients instead of temperature gradients may be beneficial for the robustness of the results, knowing the fact that ERA-40 data was reported to have biases in the temperature field due to 1997 year change in the treatment of the observations (Screen and Simmonds 2011).

Figure 6 shows the meridional gradient tendency of the $\mathrm{CI}$ anomaly at $\mathrm{Ym} 2+, \mathrm{Ym} 1+, \mathrm{Y} 0+, \mathrm{Ym} 1-$, and $\mathrm{Ym} 2-$ over the main Arctic areas that lead NAO in Fig. 4e: the Barents Sea, Laptev Sea, East Siberian- North Pacific seas, Beaufort sea-Canadian Archipelago and Greenland coasts. We first note that the tendency at $\mathrm{Ym} 1+$ (year preceding $\mathrm{NAO+}$ ) has for all domains, opposite sign to the tendency at Ym1- (years preceding NAO-), in average over the 
(a) $67 \mathrm{~N}$ (SW.Green) (b) $75 \mathrm{~N}$ (NW.Green) (c) $72 \mathrm{~N}$ (Beaufort)

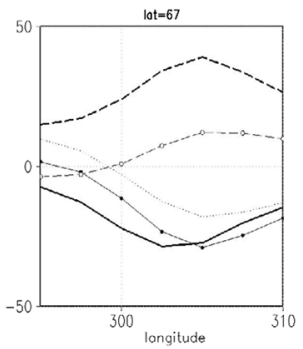

(f) $65 \mathrm{~N}$ (SE.Green)

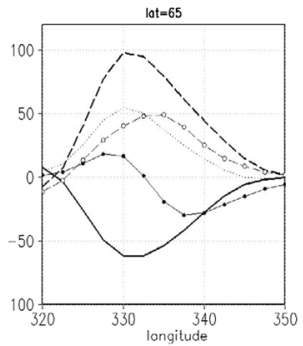

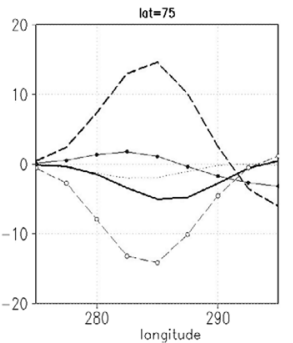

(g) $70 \mathrm{~N}$ (E.Green)

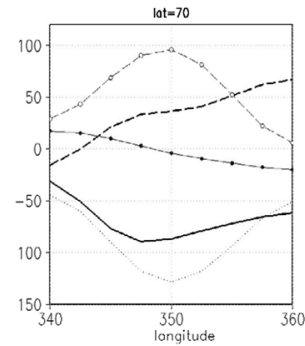

(d) $77 \mathrm{~N}$ (NE.Green)
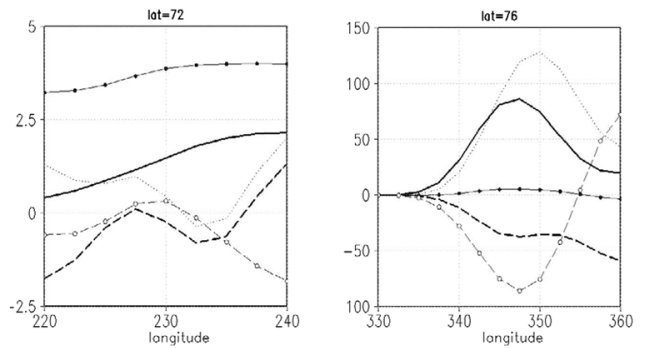

(h) $65-70 \mathrm{~N}$ (Barents)
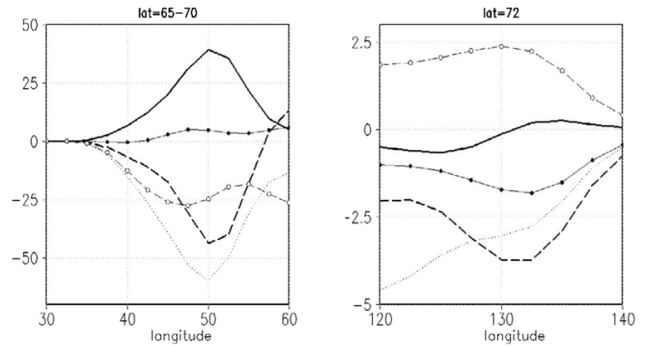

(e) $67 \mathrm{~N}$ (Chukchi)

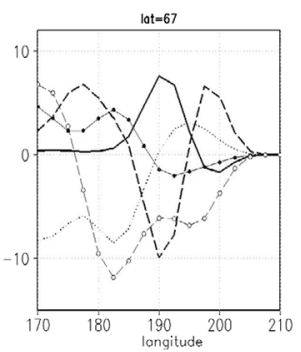

(j) $60 \mathrm{~N}$ (Bering)

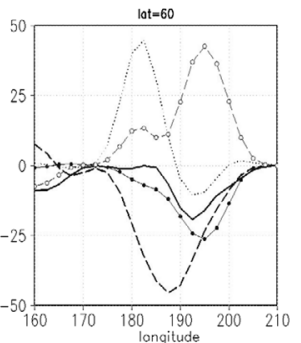

Fig. 6 Composite yearly tendency of the meridional CI gradient from ERA40 DJF slice1, valid at: Ym2- (open circle), Ym1- (thick dash line), $\mathrm{Ym} 1+$ (thick solid), $\mathrm{Ym} 2+$ (closed circle), $\mathrm{Y} 0+$ (thin dotted line). The areas are: - Greenland area: the South-West Greenland $\left(67^{\circ} \mathrm{N}, \mathbf{a}\right)$, the North-West Greenland $\left(75^{\circ} \mathrm{N}, \mathbf{b}\right)$, the South-East Greenland $\left(65^{\circ} \mathrm{N}, \mathbf{f}\right)$, the East Greenland $\left(70^{\circ} \mathrm{N}, \mathbf{g}\right)$; - and the North- ern Arctic coast: the Barents Sea $\left(65-70^{\circ} \mathrm{N}\right.$ coast, h), the Laptev Sea $\left(72^{\circ} \mathrm{N}, \mathbf{i}\right)$, the Bering-Chukchi seas $\left(60^{\circ} \mathrm{N}, \mathbf{j}\right)$ and $\left.67^{\circ} \mathrm{N}, \mathbf{e}\right)$, the Beaufort Sea $\left(72^{\circ} \mathrm{N}, \mathbf{c}\right)$ and the North-West Greenland $\left(77^{\circ} \mathrm{N}, \mathbf{d}\right)$. The $x$ axis shows the longitude, the $y$-axis the ice concentration fraction change per year in $1 . \mathrm{e}-3$ units
Fig. 7 Correlation between the meridional gradient of $\mathrm{CI}$ and the winter NAO index in the following year from: a ERA40 DJF slice1 and $\mathbf{b}$ Era-Interim DJF slice2; light shading shows positive (pink)/negative (blue) correlation; darker shading indicates significance higher than: 80 and $85 \%$; contours show levels of significance: 95 and $99 \%$. Shaded areas are smoothed using a 9 points interpolator (non-periodic with boundary at the Greenwich meridian) (a) slice1

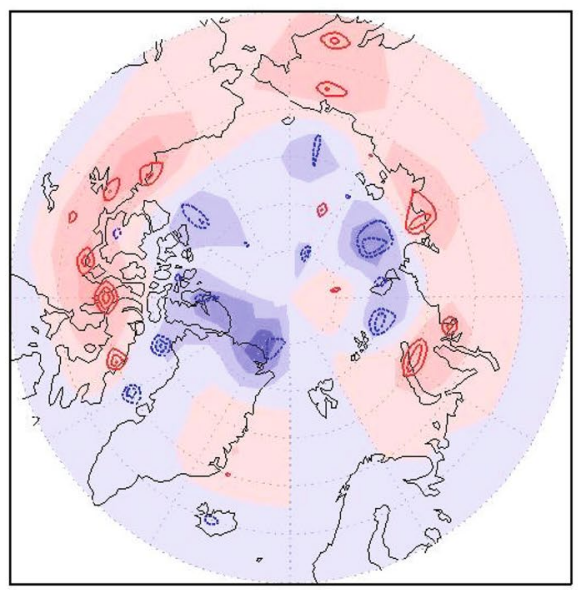

(b) slice2

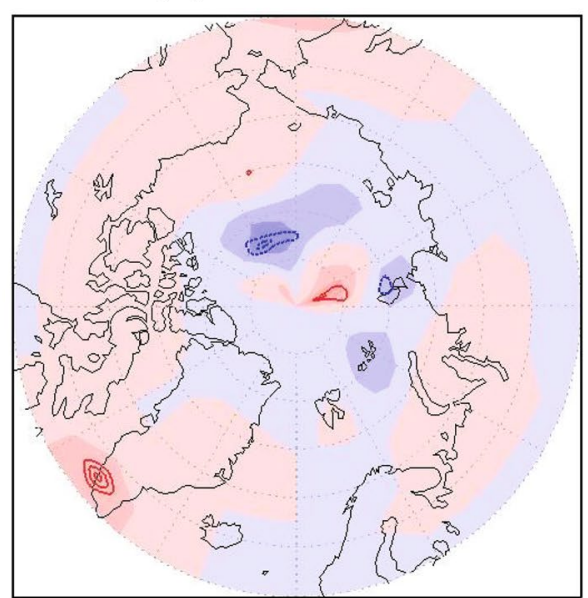

ensemble composites at 1 stdev. We further note, for most of these areas a monotonic evolution of the gradients' tendency within a NAO phase, with the sign changed at $\mathrm{YO}$. It turns out that these gradients co-vary and that the NAO phase change is led 1 year in advance by a change in the gradients tendency sign, or:

$\frac{\partial}{\partial t}\left(\nabla_{y} \mathrm{ci}\right)_{(\mathrm{Ym} 1)} \frac{\partial}{\partial t}\left(\nabla_{y} \mathrm{ci}\right)_{(Y 0)}<0$
The areas where (2) holds are: South-East and SouthWest Greenland (Fig. 6f, a), Barents Sea (Fig. 6h), Laptev Sea (Fig. 6i), West Chukchi and East Bering Seas (Fig. 6e, j) and Beaufort Sea (Fig. 6c) (exception makes the East-North-East Greenland gradients (Fig. 6g, d) that in average show a zero-lag relation to NAO). Figure 7 shows pointwise time correlations between the $\left(\nabla_{y} \mathrm{ci}\right)$ and the NAO of the following year. We note areas of potential co-variability that create an annular forcing 
over the Arctic and high-latitudes in agreement with Fig. 4e (and with the broader CSF-NAO nonlinear areas in Fig. S2). This is also required (condition 3) before the maximal NAO phase by the high pressure composites anomaly over the Arctic (Fig. 5c $2^{\text {nd }}$ row) for NAO+, and the opposite (Fig. S3c-top) for NAO-. This annular, quasi-stationary co-variability, triggers positive/negative vorticity polewards/southwards coastal Arctic when leading NAO+.

The gradients monotony seen in Fig. 6 indicates a period $\mathrm{T} \geq 5$ years of this oscillation, apart the Laptev, Beaufort and Barents seas regions where there is also a shorter period (linked to the triggering condition 3 ). It turns out that the phases of the coastal $\left(\nabla_{y} \mathrm{ci}\right)$ oscillation over persistent areas could provide useful NAO-predictive information even beyond yearly time scale.

To assess now the persistence of the Arctic-high-latitudes gradients we compute the areas with significant autocorrelation (1 year lag) for CI (Fig. 8a) and TS (Fig. 8b). Figure 8a shows that the Laptev -East Siberian seas, North Canadian Archipelago and to a less extent the North Barents Sea (the main areas involved in CI leading NAO) show
Fig. 8 Auto-correlation of: a CI in DJF-slice1ci at 1 year time lag; b same as (a) for TS; values exceeding 0.35 are significant at the $95 \%$ level (a)

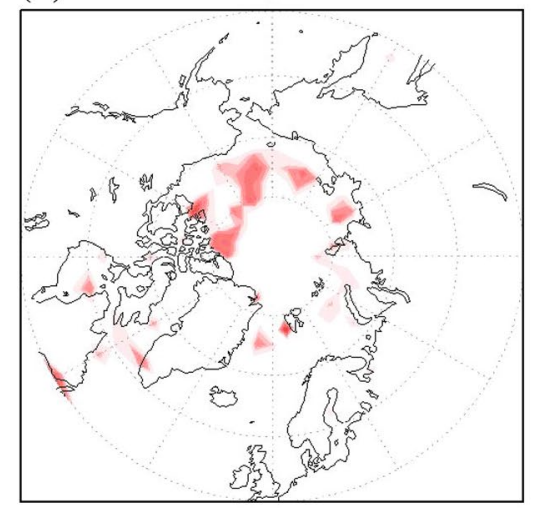

(b)

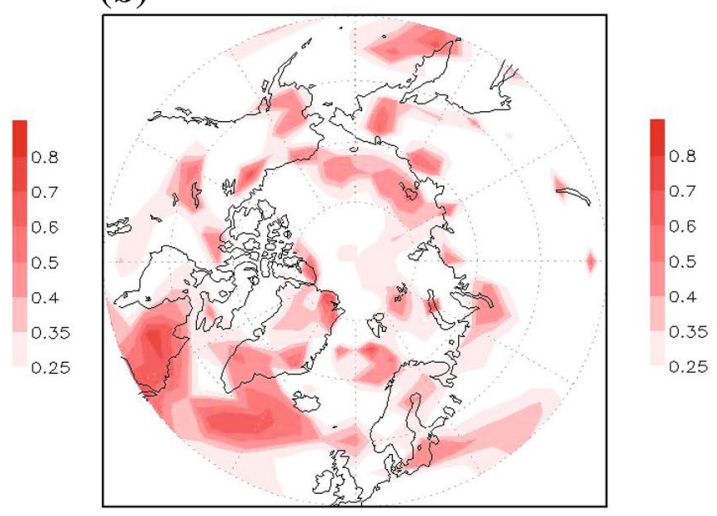

(a)

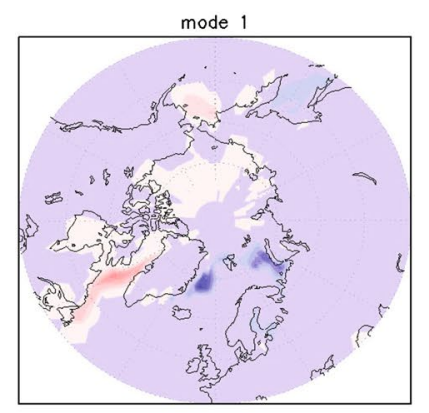

(b)

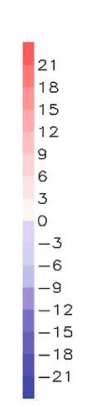

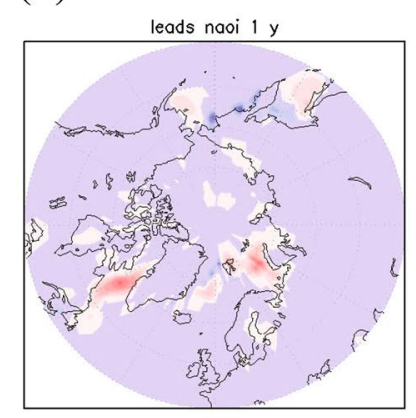

(c) $35 \mathrm{~N}-90 \mathrm{~N} \quad \mathrm{r}=0.607$

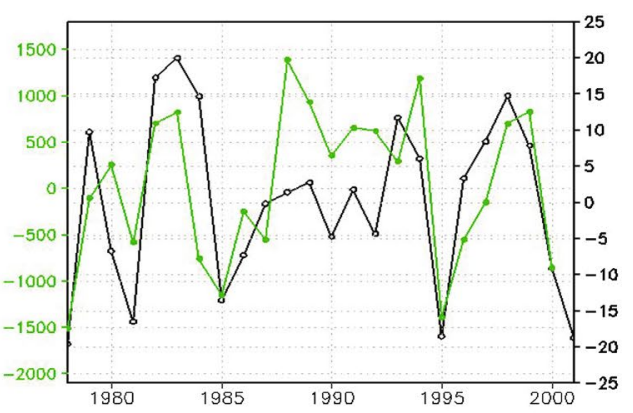

(d) NAOi slice1ci

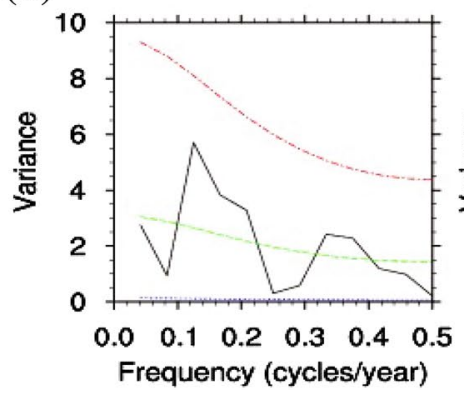

Cl_35N

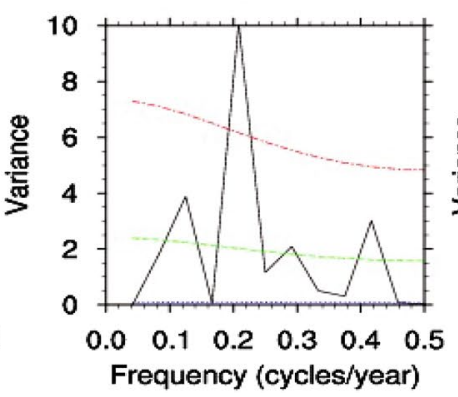

Cl_82N

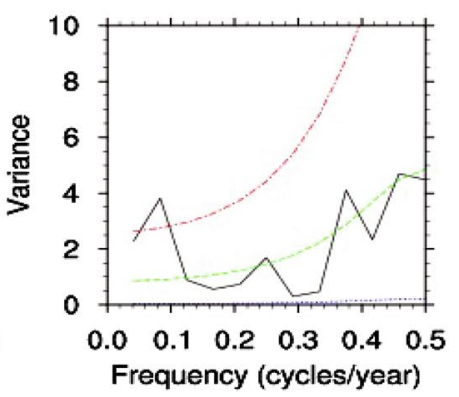

Fig. 9 a The first mode (EOF1) of CI variability over $35^{\circ} \mathrm{N}-90^{\circ} \mathrm{N}$, slice1ci; $\mathbf{b}$ the CI mode highest correlated to NAO, CI leading NAO by 1 year in slice1ci; $\mathbf{c}$ normalized time series of the PCs associated to the mode in (b) (black) and the NAO index (green) of the follow- ing year; d power spectrum (black) of the NAO index (left) and of the CI mode leading the NAO-index by 1 year over: $35^{\circ} \mathrm{N}-90^{\circ} \mathrm{N}$ and $82^{\circ} \mathrm{N}-90^{\circ} \mathrm{N}$; green lines show statistical significance at $90 \%$ level and red lines at $95 \%$ level 
significant auto-correlation. Blanchard et al. (2011) found, using satellite data for 1978-2008, an e-folding time of sea ice concentration decorrelation of approximately 5 months and a re-emergence of winter sea ice anomalies in the following fall and winter. The areas they found for Januarybased anomalies as re-emerging in September-October up to the next January (correlated at a 95\% significance level) fit geographically well (their Fig. 9) with those shown in our Fig. 8a, including a delayed re-emergence over the Barents Sea (their Fig. 2). They hypothesized that the extended signal is based on the re-emergence of sea surface temperature anomalies (due to upper ocean memory) in regions where SST is highly correlated with sea ice extent (as Barents and Okhotsk Seas regions, also better emphasised in Fig. 8b).

Since the NAO leading mechanism proposed here emphasised the role of Arctic-high latitudes meridional gradients, similar persistence areas were analysed for the first layer surface temperature. The auto-correlation areas of TS (Fig. 8b) are often consisting of a dipole with one pole near the coast over the Arctic Ocean and a second on land near the coast. The land near-coast auto-correlated anomalies correspond to memory in the permafrost (Brown et al. 2002; Hinkel and Nelson 2003; Walsh et al. 2005). Frozen ground restricts subsurface water movement and surface flow prevails, while increased runoff and freshwater delivery on the Arctic continental shelf leads to stronger sea ice formation (Forman et al. 2000). Such coupled land/ sea persistent forcing are identified over South/ North of the Eastern Laptev sea (with a correlation between CI and TS at $140^{\circ} \mathrm{E}$ North/South coast of -0.76 ), and over the Canadian Archipelago (with CI and TS correlation at $90^{\circ} \mathrm{W}$ coast of -0.44). Hence, land permafrost memory may contribute to the interannual persistence of CI anomalies [otherwise limited by memory-decay remote mechanisms, as shown by Tietsche et al. (2011)] over these two key areas. At interannual scales, Romanovskii et al. (2003) showed that permafrost variability over the Laptev and East Siberian Seas shelf and low land areas at $75^{\circ} \mathrm{N}$ is large-scale driven, emphasising a delay of the maximal permafrost thickness extremes relative to the mean annual temperature extremes over these areas.

Lower latitudes persistent TS anomalies may also be maintained as a result of snow cover-albedo feedback mainly during spring. Snow cover (positive anomaly under cyclonic conditions) over land maintains a cold near-surface anomaly due to albedo feedback. In Fig. 8b persistent TS anomalies are found over Central and Far East Asia (an area of TS leading NAO in Fig. 4g), land area of maximas in snow persistence (number of days with a snow cover of more than $50 \%$ over the last 5 decades) and snow water equivalent (Bulygina et al. 2011).
We showed that the mechanism of CI leading MSL and NAO in Figs. 4 and 5 is based on quasi-stationary meridional thermal gradients associated to persistent $\mathrm{CI}$ anomalies that force thermal wind vorticity and column-pressure adjustment to it. We further analyse the robustness of the results under a transient climate.

\section{Leading NAO under transient climate}

\subsection{Modes of ice variability leading the NAO in observed transient climate}

To extract the dominant signal from the leading correlations found in Fig. 4e and further compare it under transient climates, we analyse their co-variability using an Empirical Orthogonal Functions (EOF) analysis.

\subsubsection{Time slicelci}

We first consider CI over the slice1ci interval: 1978-2001. For this interval, an hemispheric $\left[35^{\circ} \mathrm{N}-90^{\circ} \mathrm{N}\right]$ EOF mode (EOF2) of CI variability was found (Fig. 9b) that is leading the NAO index by 1 year with a correlation $\mathrm{r}=0.607$, statistically significant at 95\% level (over 1960-2001 the correlation is 0.32 , still significant at $95 \%$ ). This mode captures the main leading areas found in Fig. 4e. The corresponding principal component time series shows that some extreme NAO events are very well captured by the CI mode leading NAO (Fig. 9c).

Sensitivity tests indicate (not shown) that the correlation and the explained variability of the CI mode leading the NAO gets lower for sub-domains further restricted latitudinally (centred over the Pole), although they preserve the main pattern. This decrease points again to a coupled process, and to the role of meridional gradients between Arctic and high-latitudes (Fig. 7), that is poorer captured by smaller domains. Meanwhile sensitivity tests indicate better driving of particular extreme events by sub-regional CI modes, longitudinally restricted, method that could be useful tool in process-analysis.

For initialised prediction also, it turns out that the skill might be improved when initialisation focuses on key regions, these being related to the target range. While the NAO index power spectrum over slice1 shows (Fig. 9d) three main periods (T) of 10,5 and 3 years [in agreement with Venegas and Mysak (2000)], domain-sensitivity analysis shows differences in the spectra of regional CI modes leading the NAO. Figure 9d shows highest statistical significance for lower latitudes in leading higher NAO frequencies ( $T=5$ years) while for higher latitudes in leading lower NAO frequencies ( $T=10$ years). 
Fig. 10 a, $\mathbf{b}$ as in Fig. 9a respectively Fig. 9b, for the slice2
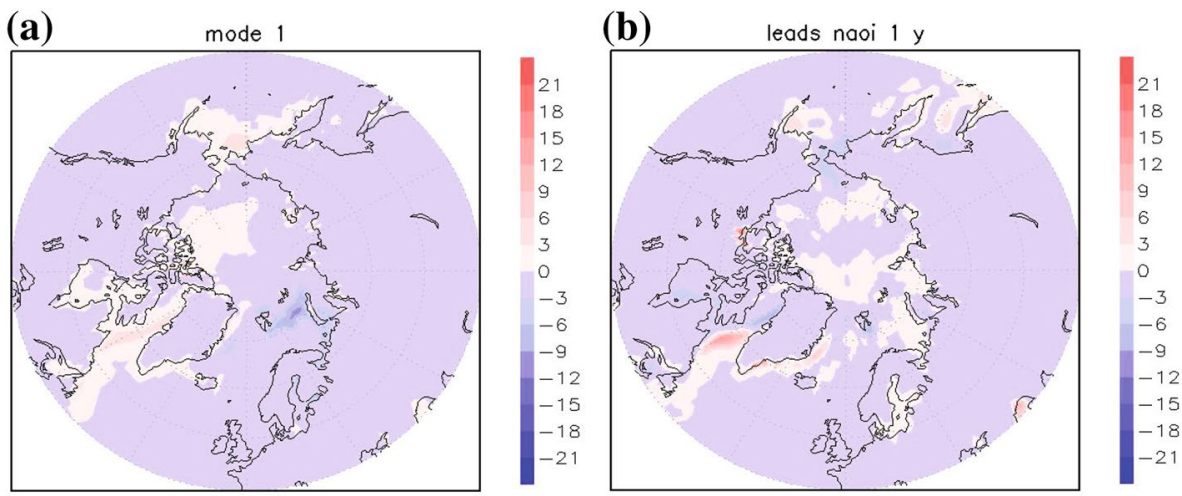

(a) MSL leads NAOi 1 y (slice2)

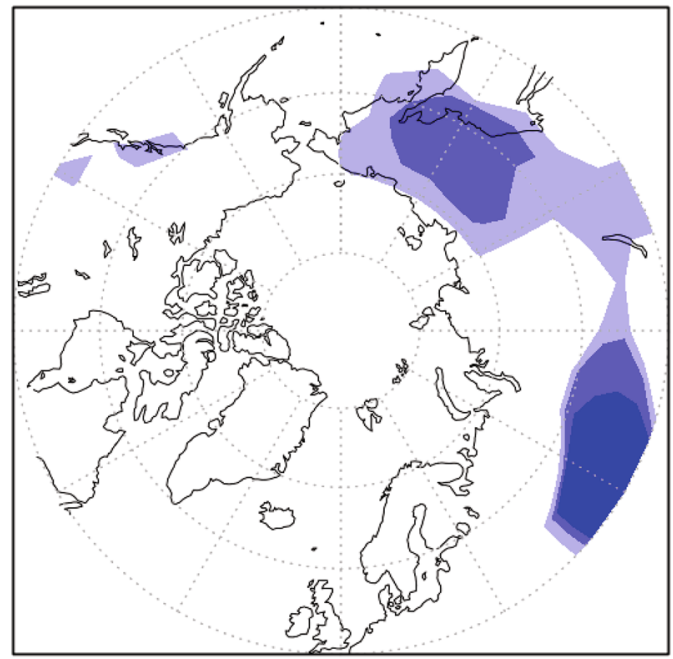

(b) CSF leads NAOi 1y (slice2)

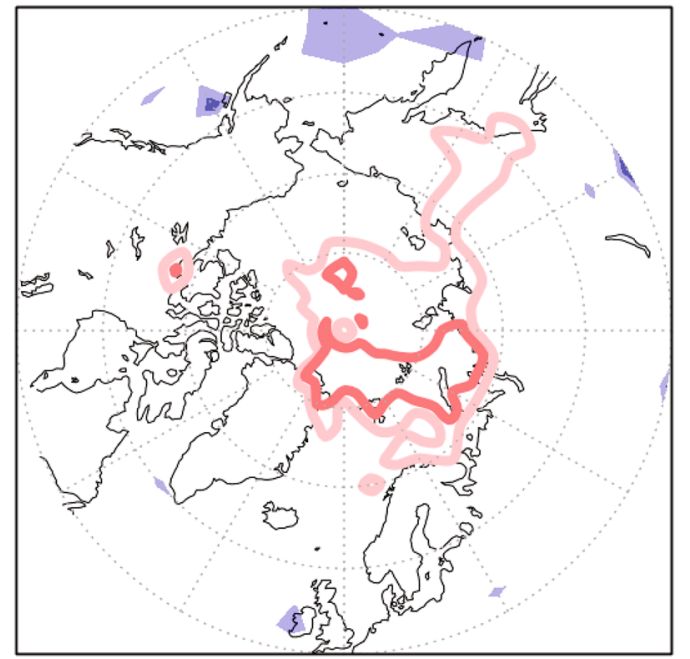

(c) $\Delta_{\mathrm{t}} \mathrm{MSL}:(\mathrm{Ym} 1+-\mathrm{Ym} 2+)($ slice2 $)$

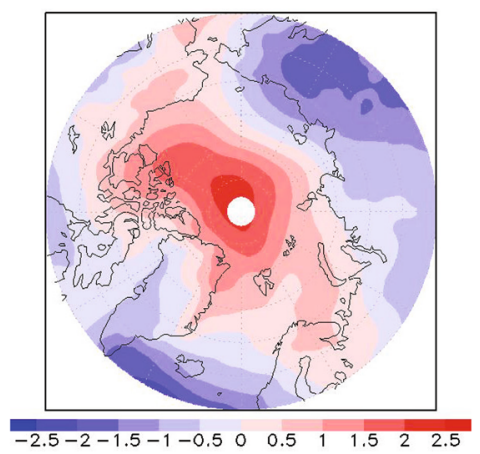

(d) $\Delta_{\mathrm{t}} \mathrm{CI}:(\mathrm{Ym} 1+-\mathrm{Ym} 2+)($ slice2)

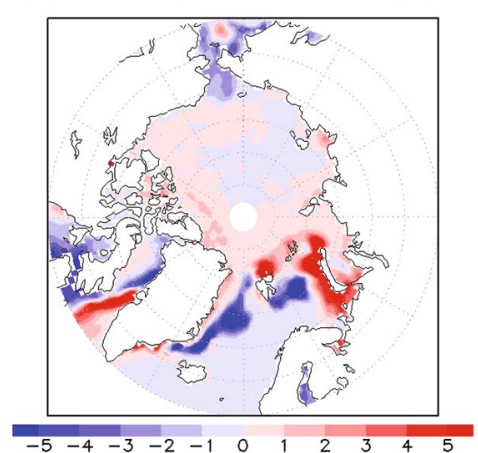

(e) $\Delta_{\mathrm{t}} \mathrm{MSL}:(\mathrm{Y0}+-\mathrm{Ym} 1+)($ slice2 $)$

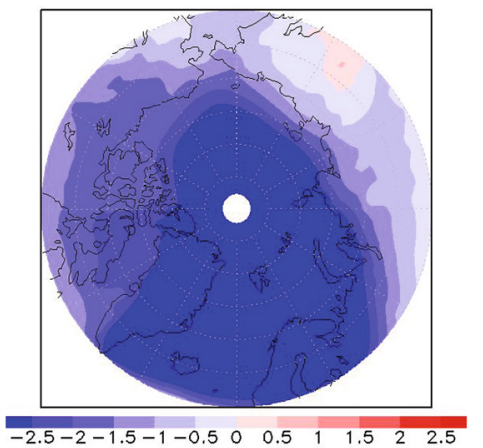

Fig. 11 a Areas of statistically significant correlations for MSL leading NAO index by 1 year, ERA-interim DJF, slice2 (colours as in Fig. 3); (b as in a) for CSF; $\mathbf{c}$ as in Fig. 5, yearly tendencies of MSL

Comparing the CI mode leading NAO+by 1 year and the CI leading mode (EOF1, that is zero-lag related to NAO, Fig. 9a) we can retrieve a good agreement of these differences (anomalies at $\mathrm{Y} 0+$ in Fig. 9a minus $\mathrm{Ym} 1+$ in Fig. 9 b) with the tendencies of the $\left(\nabla_{y}\right.$ ci $)$ in Fig. 6 at $Y 0+$. at $\mathrm{Ym} 1+([\mathrm{hPa}])$, composites from ERA-interim DJF, slice2; (d as c) for $\mathrm{CI}$ at $\mathrm{Ym} 1+([\% / \mathrm{year}]) ;(\mathbf{e}$ as c) for MSL at Y0+ ([hPa])

\subsubsection{Time slice2}

We compare now the link between CI and NAO during slice2 (the most recent time slice), against slice1ci. The main CI mode of variability in slice2 (EOF1, Fig. 10a) shows a slight eastwards shift compared to EOF1 in slice1ci 
(Fig. 9a): the Barents Sea region co-varies now with the Laptev-East Siberian seas while the North-East Greenland with the Beaufort Sea and the West Greenland. This eastward shift is hence also reflected in related regions leading the NAO, like the MSL leading NAO by 1 year (Fig. 11a) where the Central Russia $\left(80^{\circ} \mathrm{E}\right)$ pattern previously leading NAO by 2 years (Fig. 3d) is now leading it by 1 year when extends over Siberia. This shift in slice2 is in agreement with a non-stationarity of the autumn-winter teleconnection between Eurasia snow cover and NAO, whose occurrence in recent reanalysis prevails after the 1970s, as noticed by Peings et al. (2013). In the same way in the warmer climate of slice2, new NAO leading areas of significance (yet preserving the annularity of the CI gradients) appear over the new open water edges (Fig. 10b, compared to Fig. 9b): the North Greenland-Svalbard-Franz Josef, the Western Laptev Sea, the Canadian Archipelago-as also reflected in the CSF field (Fig. 11b compared to Fig. 3b).

It is interesting to note that in spite of these changes the CI mode that leads the NAO by 1 year (Fig. 10b) in slice2 represents the same leading mechanism. This matches the same CI co-variability over the three key leading regions found in the nonlinear analysis and in the slice1ci: the axis Canadian Archipelago-Labrador Sea/East Siberian Sea-Okhotsk Sea and East Barents Sea. These regions are again, related to high pressure anomaly 1 year before a NAO+over the North Greenland-Canadian Archipelago and the Laptev Sea, a constant feature also in slice2 (Fig. 11c). These trigger the two main responses seen in slice1. One is the cold advections over Western side of Northern oceans, evaporation and transport Eastwards. The other is the cold coastal anomaly driven by the high pressure anomaly over the Central Arctic (Figs. 7b, 11d). These two create a quasi-annular meridional thermal gradient high/mid latitudes that leads positive vorticity over the Central Arctic the following winter (Fig. 11e).

The changes in the $\mathrm{CI}$ forcing at $\mathrm{Ym} 1$ are reflected also in the response at $\mathrm{Y} 0$. We note in Fig. 12, for Y0+ composites over same time-length sub-slices of slice1 and slice2, a clear North-Eastward shift of the Iceland low centre that
Fig. 12 MSL (contour $[\mathrm{hPa}]$ ) and TS anomalies (shaded $[\mathrm{K}]$ ) averaged for composites at 1 standard deviation of years Y0+ in ERA DJF data, 35 yeartime series of (a) slice1 and (b) slice2 (a)

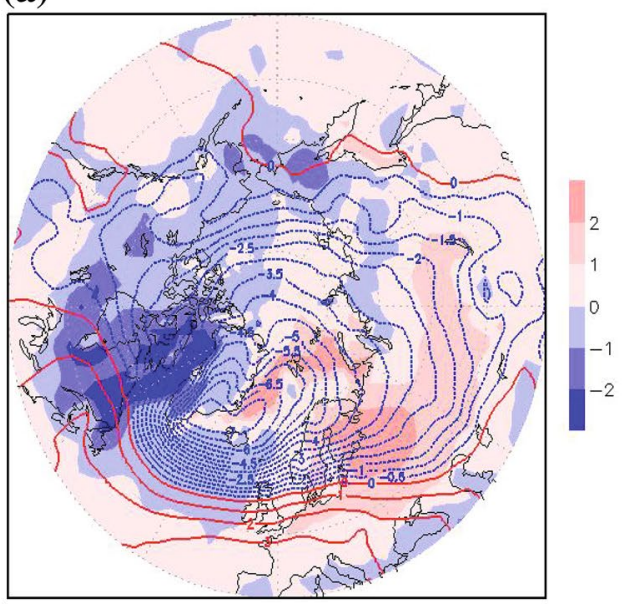

(b)

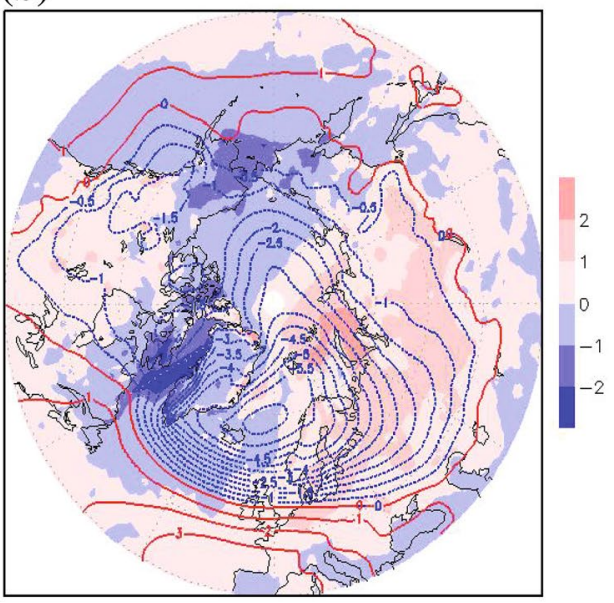

(a)

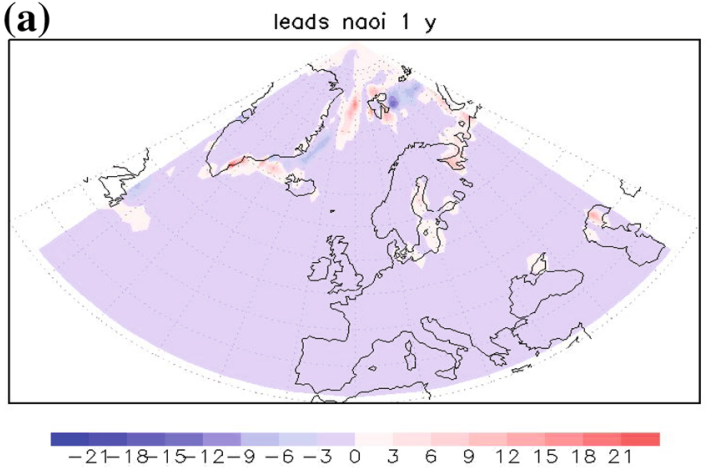

(b)

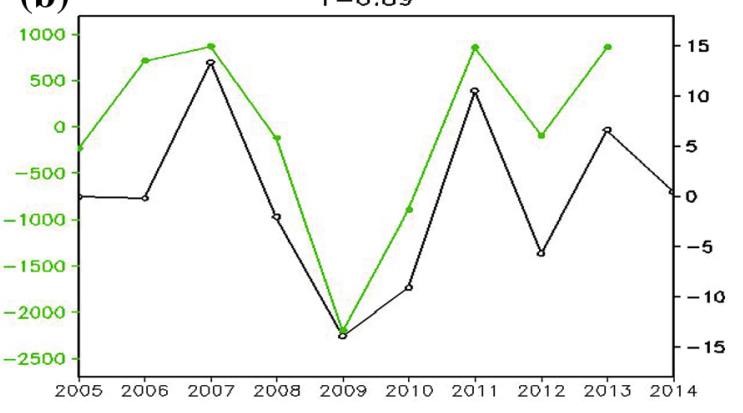

Fig. 13 a: The regional winter CI-EOF mode (ERA-Interim) highest correlated with the NAO index of the following year over 2005-2014; b: time series of this mode (black) and of the NAO index in the following year (green, $[\mathrm{Pa}]$ ) 
enhances a secondary axis North-Scandinavia-East Black Sea. This makes a more zonal flow over the North Atlantic and over the Western Europe (instead of South-WestNorth-East) and brings colder winters in average over this area. This shift affects the whole wavenumber 4 pattern at high latitudes (Fig. 12a), developing a main branch over North Pacific (instead of Far-East Asia) and damping the West USA one, with warmer Western USA and colder advection over Eastern USA (Fig. 12a, b) during NAO+.

\subsubsection{The decade 2005-2014}

The last decade 2005-2014 was characterized by extreme variations in the AO/NAO index. The zonal hemispheric CI mode shown to lead the NAO index by 1 year during slice 2 , only captures in part 1 year in advance, the decade's NAO variability. However, a regional analysis emphasizes a CI sub-domain that maximises the 1 year leading correlation over the decade. This regional mode, shown in Fig. 13a, fits very well, over the common areas $\left(55^{\circ} \mathrm{W}-55^{\circ} \mathrm{E} \times 35^{\circ} \mathrm{N}-90^{\circ} \mathrm{N}\right)$, the: CI co-variability in Figs. 10b and 11d (over Labrador, Odden and Barents areas), the CI gradients in Fig. $7 \mathrm{~b}$ and is also, as expected, in agreement with the tendency of $\left(\nabla_{y} \mathrm{ci}\right)$ at Y0+ in Fig. 6g, d, h when compared to EOF1 in Fig. 10a.

The time correlation of this mode leading NAO by 1 year is high $(r=0.89$, Fig. 13b). The mode leads well the interannual variability of the decade, specifically predicting the high index in 2007-2008 and 2011-2012 and the extremely low index in 2009-2010 DJFs. Sourceareas for NAO extremes over the decade may be further investigated by subdomain-sensitivity analysis. As an example we found that the inclusion of the Davis strait eastern coast-Labrador Sea area $\left(\left[55^{\circ} \mathrm{W}-40^{\circ} \mathrm{W}\right]\right.$ area of high leading correlation in Fig. 7b) had an important role in leading the 2007 maxima. Some other extreme events studies support this: the Labrador Sea was extremely cold and severe ice formed at the south-western Greenland coast in the winters of December 1971-January 1972 and February 1982-October 1984 (Rogers et al. 1998 their Fig. 4), followed by winters when the Icelandic low was unusually deep (NAO+). The opposite was seen during the 1994-1995 DJF, followed by the extreme NAO- in 1996 winter (Deser et al. 2002). Although the correlation found is high, the prediction skill gain from a

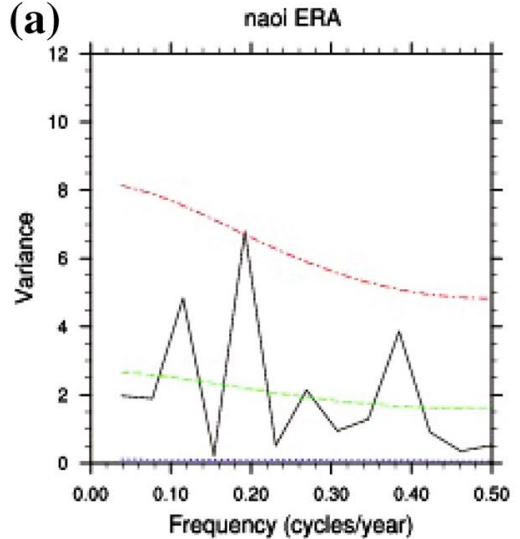

(d)

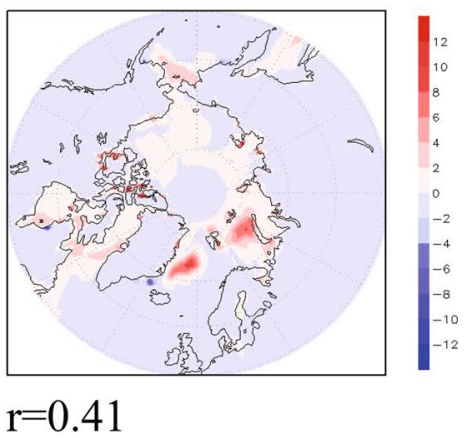

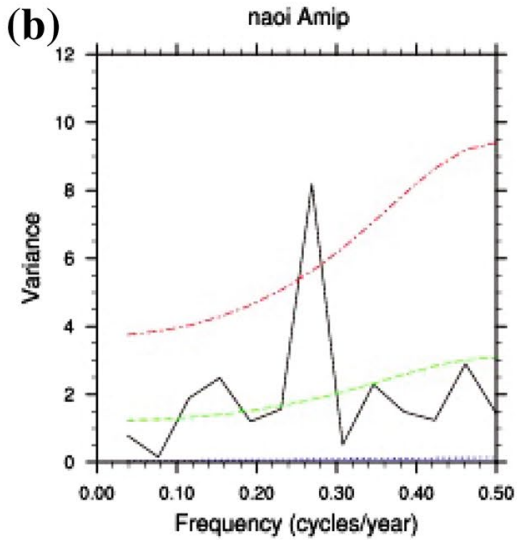

(e)

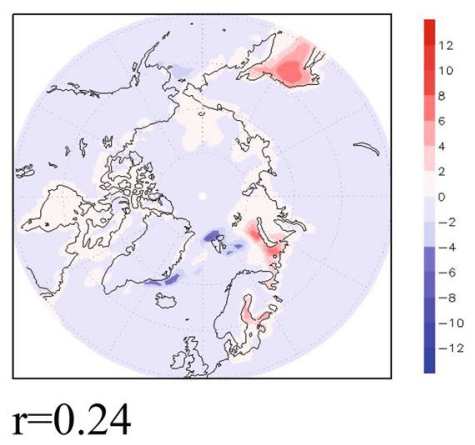

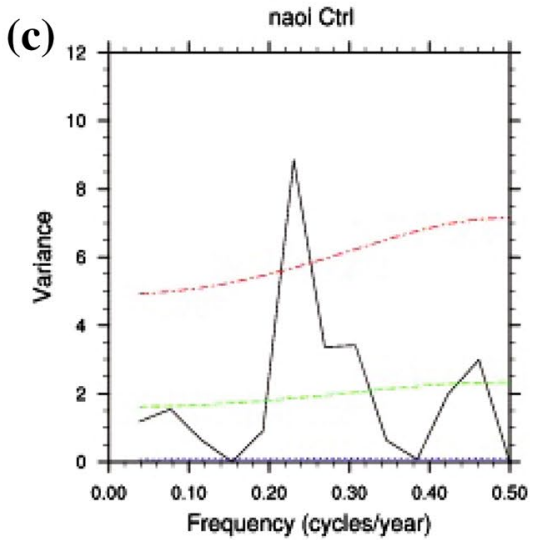

(f)

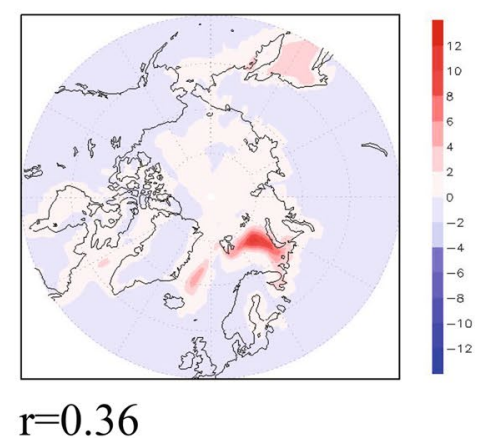

Fig. 14 Top: Power spectrum of the NAO index (DJF) in: a ERAInterim, b EC-Earth AMIP run and c EC-Earth Ctrl run over the slice $2 \mathrm{~m}$ (1980-2005). Statistical significance is shown at confidence level 95\% (red), 90\% (green) and 85\% (blue); $\mathbf{d}$ the winter CI ([\%]) mode of variability highest correlated (correlation " $\mathrm{r}$ " at bottom) with the following winter NAO index over 1980-2005 for ERA-Interim, slice2m; same as d) for: the AMIP run (e) and for the Ctrl run (f) 
proper initialisation of this mode remains a difficult task. Moreover, one should carefully account for other known NAO sources (e.g. the tropical Pacific, as shown by Dunstone et al. 2016), and consider its interaction with these sources.

\subsection{Modes of ice variability leading the NAO in models}

We have shown that the mechanism found for yearly leading NAO remains robust under transient climate (slice2). We wonder then if actual models are able to reproduce this mechanism when leading own NAO phases. We use the EC-Earth model for this analysis. Figure 14 shows the CI mode (EOF) that leads the simulated NAO index by 1 year with statistically $95 \%$ significant correlation, for two cases. In one case we used the atmospheric model component with a slab ocean with predefined SST and CI (Amip, Fig. 14b) and for the other one we used a fully coupled control simulation (Ctrl) of the model (Fig. 14c). The period of the comparison is 1980-2005 (slice2m). In both cases the CI mode leading NAO captures the main spatial pattern of co-variability that leads the NAO in the observations (Fig. 14a).

Having a same leading mechanism for the Amip, Ctrl and observations is an expected feature: the mechanism should not be dependent on the forcing data but on meeting the leading pre-conditionning (e.g. the annular coastal forcing by meridional thermal gradients, triggered by pressure dipole at the North-Western oceans and associated anomalous latent heat advection). Hence it would be expected to be reproduced also using constant, climatic forcing. When annular, persistent meridional negative thermal gradients about the Arctic coast are achieved, this will lead cyclonic vorticity over the Arctic for any type of data.

However the leading correlation is lower for Amip than for Ctrl, presumably because while the pressure adjustment can be driven by steady CI gradients (as thermal meridional gradient varies), it cannot feedback on CI in the Amip case. This provides a lower coupling by the meridional gradients than in the Ctrl case, changes in the persistence of the forcing (Perovich 2011) and in the wave dynamics. For example, an opposite response than observed one was found over the Greenland-Barents Seas by Alexander et al. (2004) and Magnusdottir et al. (2004) when forcing the model with observed SST and sea ice data.

Different wave-dynamics are expected to result in different spectral properties of the leading for the observations, Amip or the Ctrl run. Indeed, comparing the power spectra of the observed (Fig. 14a) and simulated NAO index (Fig. 14b, c), we find that the main significant NAO period $\mathrm{T} \sim 5$ years in ERA slice2m data is more accurately represented in the Ctrl simulation (Fig. 14c) while in the Amip case the model's NAO has a slightly higher frequency (period of about 4 years, Fig. 14b). The decadal period (10 years in ERA slice2m) peaks at about 12 years and has less significance in Ctrl, and at only 7 years in the Amip run. In addition we note slight NAO spectral changes during a warmer climate (lower significance of slow oscillations at $\mathrm{T} \sim 10$ years and increased significance of higher frequency at $\mathrm{T} \sim 5$ years in Fig. 14a compared to Fig. 9d), that may also contribute to spectra differences between model and observations, from forcing inaccuracies.

\section{Conclusions}

The aim of the work was to establish causal links between Arctic sea-ice and NAO on interannual time scale, and to analyse associated mechanisms. To select responsible processes we first identified physical variables and geographical areas of Arctic variability nonlinearly related to the NAO. We then analysed the mechanisms potentially contributing over these areas to drive NAO phase transitions. We showed that Arctic sub-regions exist, with an apparent robust link, relating the yearly DJF sea-ice concentration anomalies to the NAO index of the following winter. The extended leading is based on the persistence of thermal meridional gradients associated to surface anomalies and heat fluxes.

We showed that such a quasi-stationary surface forcing triggers slow equivalent-barotropic mass adjustment with pressure drop over cold anomaly. This adjustment is a response to the column vorticity generated by the thermal winds associated to the surface anomalies. Further, this change in pressure feeds-back on the ice anomalies propagation, enabling so a potential oscillatory mechanism. This oscillation is seen in a quite periodic forcing by sea-ice coastal meridional gradients.

The spatial pattern of those CI persistent anomalies that lead the NAO by 1 year is quasi-annular about the Arctichigh latitudes coast, extending over the West Baffin BayDavis Strait-Labrador coast and the North-East Okhotsk sea (with positive anomalies leading the NAO positive phase). The maximal phase of this co-variability is triggered when a high pressure anomaly develops 1 year before the NAO+ (low pressure for NAO-) over the Central Arctic extending over North Greenland-Canadian Archipelago-Baffin Bay with centres also over the Laptev Sea and North Barents Sea. This "Arctic bridge" appears as a preconditioning feature of the maximal NAO phase, being systematic under transient climates. Its role is linked to cold advection over both: the North-Western Atlantic and NorthWestern Pacific with evaporative ocean cooling, low pressure formation and persistent latent heat advection over the mid-latitudes land. So a persistent, annular, negative meridional thermal gradient is achieved about the Arctic coast, 
leading positive vorticity over Central Arctic the following year (when leading $\mathrm{NAO}+$ ). A mode of CI variability captures this pattern and is leading the NAO index by 1 year, having similar spectral properties to the NAO index. The highest leading correlation of this mode is obtained over $\left(\left[35^{\circ} \mathrm{N}-90^{\circ} \mathrm{N}\right]\right)$, domain that couples the Arctic with the high-latitudes.

During 1980-2014 the leading areas show a slight eastwards shift, linked to changes in the CI variability (mainly over the Central Arctic-North-Barents Sea). Contrary to these changes, the mechanisms of CI leading NAO is unchanged in the warmer climate. It turns out that its representation in models may provide an important source of skill. In a numerical experiment we show that the coupled EC-Earth model reproduces the same mechanism of CI leading NAO with pattern, correlation and spectral properties of the relevant mode, similar to the ones shown in reanalysis. When forcing the EC-Earth atmosphere by prescribed SST and CI, the NAO leading correlation is lower than in the coupled model (below 95\% p-level statistical significance) sustaining the role of sea-ice-atmospheric pressure feedback.

The results discussed here point to specific Arctic-high latitudes regions that need to be accurately initialized, and to the need of a consistent high latitudes-Arctic coupled initialization in order to increase the model-skill of NAO prediction. The NAO leading mechanism indicates that an accurate initialisation of the meridional thermal gradients over the model's leading areas, would drive the NAO, at least the following year, towards a correct phase. This is expected also to provide an improved representation of teleconnected regions and further improve the prediction skill on multi-annual range.

Acknowledgements We would like to thank the EC-Earth community for providing the GCM used in the numerical simulations. This work is part of the SPECS project funded by the European Union's Seventh Program for research, technological development and demonstration under grant agreement No 308378 (SPECS). The simulations were performed on resources provided by the Swedish National Infrastructure for Computing (SNIC) at NSC and PDC. We thank anonymous reviewers for their very useful comments on the manuscript.

Open Access This article is distributed under the terms of the Creative Commons Attribution 4.0 International License (http:// creativecommons.org/licenses/by/4.0/), which permits unrestricted use, distribution, and reproduction in any medium, provided you give appropriate credit to the original author(s) and the source, provide a link to the Creative Commons license, and indicate if changes were made.

\section{References}

Aarten M, Ambaum HP, Hoskins BJ, Stephenson DB (2001) Arctic Oscillation or North Atlantic Oscillation? J Clim 15:3495-3507
Alexander MA, Bhatt US, Walsh JE, Timlin MS, Miller JS, Scott JD (2004) The atmospheric response to realistic Arctic sea ice anomalies in an AGCM during winter. J Clim 17:890-904

Allen RJ, Zender CS (2011a) Forcing of the Arctic Oscillation by Eurasian snow cover. J Clim 24:6528-6539

Allen R, Zender CS (2011b) The role of eastern Siberian snow and soil moisture anomalies in quasi-biennial persistence of the Arctic and North Atlantic Oscillations. J Geophys Res 116:D16125. doi:10.1029/2010JD015311

Ambaum MB, Hoskins B, Stephenson D (2001) Arctic oscillation or North Atlantic Ocsillation? J Clim 14:495-3507

Bader J, Mesquita M Hodges K, Keenlyside N, Osterhus S, Miles M (2011) A review on Northern Hemisphere sea-ice, storminess and the North Atlantic Oscillation: observations and projected changes. Atmos Res 101:809-834

Barnes EA (2013) Revisiting the evidence linking Arctic amplification to extreme weather in mid-latitudes. Geophys Res Lett 40:4734-4739. doi:10.1002/grl.50880

Benedict JJ, Lee S, Feldstein SB (2004) Synoptic view of the North Atlantic interactive oscillation. J Atmos Sci 61:121-144

Blanchard-Wrigglesworth E, Armour KC, Bitz CM, Deaweaver E (2011) Persistence and inherent predictability of Arctic sea ice in a GCM ensemble and observations. J Clim 24:231-250. doi:10.1 175/2010JCLI3775.1

Bojariu R, Gimeno L (2003) The role of snow cover fluctuations in multiannual NAO persistence. Geophy Res Lett 30(4):156. doi:1 0.1029/2002GL015651

Bouillon S, Morales Maqueda MA, Legat V, Fichefet T (2009) An elastic-viscous-plastic sea ice model formulated on Arakawa B and C grids. Ocean Model 27:174-184. doi:10.1016/j. ocemod.2009.01.004

Brown J, Ferrians O, Heginbottom JA, Melnikov E (2002) CircumArctic map of permafrost and ground-ice conditions. Boulder, Colorado USA, National Snow and Ice Data Center

Budikova D (2009) Role of Arctic sea ice in global atmospheric circulation: a review. Global Planet Change 68:149-163

Bulygina ON, Groisman PY, Razuvaev VN, Korshunova NN (2011) Changes in snow cover characteristics over Northern Eurasia since 1966. Environ Res Lett 6:1-10, Article ID 045204. doi:10.1088/1748-9326/6/4/045204

Cavalieri DJ, Parkinson CL (2012) Arctic sea-ice variability and trends, 1979.2010. The Cryosphere 6:881-889. doi:10.5194/ tc-6-881-2012

Cohen J, Barlow M (2005) The NAO, the AO, and global warming: how closely related? J Clim 18:4498-4513

Cohen J, Entekhabi D (1999) Eurasian snow cover variability and Northern Hemishpere climate predictability. Geophys Res Lett 26(3):345-348

Cohen J, Screen JA, Furtado JC, Barlow M, Whittleston D, Coumou D, Francis J, Dethloff K, Entekhabi D, Overland J, Jones J (2014) Recent Arctic amplification and extreme mid-latitude weather. Nature Geosci 7:627-637. doi:10.1038/ngeo2234

Dee DP et al (2011) The ERA-Interim reanalysis: configuration and performance of the data assimilation system. Q J R Meteorol Soc 137(656, Part A):553-597. doi:10.1002/qj.828

Deser C, Walsh JE, Timlin MS (2000) Arctic Sea ice variability in the context of recent atmospheric circulation trends. J Clim 13(3):617-633

Deser C, Holland M, Reverdin G, Timlin M (2002) Decadal variations in Labrador Sea ice cover and North Atlantic sea surface temperatures. J Geophy Res 107(C5):3-1-3-12. doi:10.1029/20 00JC000683

Deser C, Teng H (2008) Evolution of Arctic sea ice concentration trends and the role of atmospheric circulation forcing, 19792007. Geophys Res Lett 35(2):1-5, Article ID L02504. doi:10.1 029/2007GL032023 
Deser C, Magnusdottir G, Saravanan R, Phillips A (2004) The effects of north Atlantic SST and sea ice anomalies on the winter circulation in CCM3. Part II: direct and indirect components of the response. J Clim 17:877-889

Deser C, Tomas RA, Peng S (2007) The transient atmospheric circulation response to North Atlantic SST and sea ice anomalies. J Clim 20(18):4751-4767

Dethloff K, Rinke A, Benkel A, Køltzow M, Sokolova E, Saha SK, Handorf D, Dorn W, Rockel B, von Storch H, Haugen JE, Røed LP, Roeckner E, Christensen JH, Stendel M (2006) A dynamical link between the Arctic and the global climate system. Geophys Res Lett 33:L03703. doi:10.1029/2005GL025245

Dunstone N, Smith D, Scaife A, Hermanson L, Eade R, Robinson N, Andrews M, Knight J (2016). Skilful predictions of the winter North Atlantic Oscillation one year ahead. Nature Geosci 9:809_ 814. doi:10.1038/ngeo2824

Forman SL, Maslowski W, Andrews JT, Lubinski D, Steele M, Zhang J, Lammers R, Peterson B (2000) Researchers explore Arctic freshwater's role in ocean circulation. EOS Trans AGU 81(16): $169-174$

Francis JA, Vavrus SJ (2012) Evidence linking Arctic amplification to extreme weather in mid-latitudes. Geophys Res Lett 39:(L06801). doi:10.1029/2012GL051000

Gerdes R (2006) Atmospheric response to changes in Arctic sea ice thickness. Geophy Res Lett 33(18):1-4, Article ID L18709. doi:10.1029/2006GL27146

Hazeleger W, Wang X, Severijns C, Stefanescu S, Bintanja R, Sterl A, Wyser K, Semmler T, Yang S, van den Hurk B, van Noije T, van der Linden E, van der Wiel K (2012) EC-Earth V2.2: description and validation of a new seamless Earth system prediction model Clim Dyn 39:2611-2629. doi:10.1007/s00382-011-1228-5

Herman GF, Johnson WT (1978) The sensitivity of the general circulation to Arc-tic sea ice boundaries: a numerical experiment. Mon Weather Rev 106:1649-1664

Hinkel KM, Nelson FE (2003) Spatial and temporal patterns of active layer thickness at Circumpolar active layer monitoring (CALM) sites in northern Alaska, 1995-2000. J Geophys Res 108(D2):8168. doi:10.1029/2001JD000927

Honda M, Yamazaki K, Tachibana Y, Takeuchi K (1996) Influence of Okhotsk sea-ice extent on atmospheric circulation. Geophy Res Lett 23(24):3595-3598

Honda M, Yamazaki K, Nakamura H, Takeuchi K (1999) Dynamic and thermo-dynamic characteristics of atmospheric response to anomalous sea-ice extent in the Sea of Okhotsk. J Clim 12:3347-3358

Hopsch S, Cohen J, Dethloff K (2012) Analysis of a link between fall Arctic sea ice concentration and atmospheric patterns in the following winter. Tellus A 64(18624). doi: 10.3402/tellusa. v64i0.18264

Huang J, Higuchi K, Shabbar A (1998) The relationship between the North Atlantic Oscillation and El Niño-Southern Oscillation. Geophy Res Lett 25(14):2461-2760

Hurrell JW, Kushnir Y, Ottersen G, Visbeck M (eds.) (2003) The North Atlantic Oscillation: climate significance and environmental impact. Amer Geophys Union Geophysical Monograph Series (134), pp 279. ISSN: 0065-8448; ISBN: 0-87590-994-9

Jeffrey CR, Hung MP (2008) The Odden ice feature of the Greenland Sea and its association with atmospheric pressure, wind, and surface flux variability from reanalyses. Geophys Res Lett 35:L08504. doi:10.1029/2007GL032938

Kållberg P, Simmons A, Uppala S, Fuentes M (2004) The ERA-40 archive. ERA-40 Project Report Series, ECMWF, Reading, 2004

Koenigk T, Mikolajewicz U, Haak H, Jungclaus J (2006) Variability of Fram Strait sea ice export: causes, impacts and feedbacks in a coupled climate model. Clim Dyn 26:17-34. doi:10.1007/ s00382-005-0060-1
Koenigk T, Brodeau L, Graversen RG, Karlsson J, Svensson G, Tjernström M, Willen U, Wyser K (2013) Arctic climate change in 21st century CMIP5 simulations with EC-Earth. Clim Dyn 40:2720-2742. doi:10.1007/s00382-012-1505-y

Koenigk T, Caian M, Nikulin G, Schimanke S (2016) Regional Arctic sea ice variations as predictor for winter climate conditions. Clim Dyn. (2016) 46:317-337. doi:10.1007/ s00382-015-2586-1

Kvamstö NG, Skeie P, Stephenson DB (2004) Large-scale impact of localized Labrador sea-ice changes on the North Atlantic Oscillation. Int J Climatol 24:603-612

Liu Z, Alexander M (2007) Atmospheric bridge, oceanic tunnel, and global climate teleconnections. Reviews in Geophy 45:RG2005RG000172

Madec G, Delecluse P, Imbard M Lévy C (1998) "OPA 8.1 Ocean General Circulation Model reference manual". Note du Pole de modélisation, Institut Pierre-Simon Laplace (IPSL), France, No 11, pp 91

Magnusdottir G, Deser C, Saravanan R (2004) The effects of north Atlantic SST and sea ice anomalies on the winter circulation in CCM3. Part I: Main features and stormtrack characteristics of the response. J Clim 17:857-875

Martin T, Martin T (2006) Anomalies of sea-ice transports in the Arctic. Ann Glaciol 44:310-316

Molteni F, Stockdale T, Balmaseda M, Balsamo G, Buizza R, FerrantiL, Magnusson L, Mogensen K, Palmer T, Vitart F (2011) The new ECMWF seasonal forecast system (System 4). ECMWF TM-656

Murray RJ, Simmonds I (1995) Responses of climate and cyclones to reductions in Arctic winter sea ice. J Geophys Res 100:4791-4806

Overland JE, Wang M (2010) Large-scale atmospheric circulation changes are associated with the recent loss of Arctic sea ice. Tellus 62:1-9. doi:10.1111/j.1600-0870.2009.00421.x

Park J, Dusek G (2013) ENSO components of the Atlantic multidecadal oscillation and their relation to North Atlantic interannual coastal sea level anomalies. Ocean Sci 9:535-543. doi:10.5194/ os-9-535-2013

Park S, Leovy CB (2000) Winter North Atlantic low cloud anomalies associated with the northern hemisphere annular mode. Geophys Res Lett 27(20):3357-3360

Parkinson CL, Rind D, Healy RJ, Martinson DG (2001) The impact of sea ice concentration accuracies on climate model simulations with the GISS GCM. J Clim 14:2606-2623

Peings Y., Brun E, Mauvais V, Douville H (2013) How stationary is the relationship between Siberian snow and Arctic Oscillation over the 20th century? Geophy Res Lett 40:183-188. doi:10.10 29/2012GL054083

Peng S, Robinson WA (2001) Relationships between atmospheric internal variability and the responses to an extratropical SST anomaly. J Clim 14:2943-2959

Perovich D (2011) The changing Arctic Sea ice cover. Oceanography 24(3):162-173

Petoukhov V, Semenov VA (2010) A link between reduced BarentsKara sea ice and cold winter extremes over northern continents. J Geophys Res 115:1-11, Article ID D21111. doi:10.1029/200 9JD013568

Petrie R., Shaffrey LC, Sutton RT (2015) Atmospheric response in summer linked to recent Arctic sea ice loss. Q J R Meterolog Soc 141(691):2070-2076

Raymo ME, Rind D, Riddiman WF (1990) Climatic effects of reduced Arctic sea ice limits in the Giss II general circulation model. Paleoceanography 5(3):367-382. doi:10.1029/ PA005i003p00367

Rogers JC, Hung MP (2008) The Odden ice feature of the Greenland Sea and its association with atmospheric pressure, wind, and 
surface flux variability from reanalyses. Geophy Res Lett 35:15, Article ID L08504. doi:10.1029/2007GL032938

Rogers JC, Wang CC, McHugh C (1998) Persistent cold climatic episodes around Greenland and Baffin Island: links to decadalscale sea surface temperature anomalies. Geophys Res Lett 25:3971-3974

Romanovskii NN, Hubberten HW, Kholodov AL, Romanovsky VE (2003) Permafrost evolution under the influence of long-term climate fluctuations and glacio-eustatic sea-level variation: region of Laptev and East Siberian Seas, Russia. In: Phillips M, Springman SM, Arenson LU (eds) Permafrost. Swets \& Zeitlinger, Lisse, ISBN 9058095827

Royer JF, Planton S, Déqué M (1990) A sensitivity experiment for the removal of Arctic sea ice with the French spectral general circulation model. Clim Dyn 5:1-17

Scaife AA, Arribas A, Blockley E, Brookshaw A, Clark R, Dunstone N, Eade R, Fereday D, Folland C, Gordon M, Hermanson L, Knight J, Lea D, MacLachlan C, Maidems A, Peterson A, Smith D, Vellinga M, Wallace E, Waters J, Williams A (2014) Skillful long-range prediction of European and North American winters. Geophys Res Lett 41:2514-2519. doi:10.1002/2014GL059637

Screen JA (2014) Arctic amplification decreases temperature variance in northern mid- to high-latitudes. Nature Clim Change 4:577582. doi:10.1038/NCLIMATE2268

Screen J, Simmonds I (2011) Erroneous arctic temperature trends in the ERA-40 reanalysis: a closer loock. J Clim 24:2620-2627

Semenov VA, Latif M, Jungclaus JH, Park W (2008) Is the observed NAO variability during the instrumental record unusual? Geophys Res Lett 35:L11701. doi:10.1029/2008GL033273

Semmler T, McGrath R, Wang S (2012) The impact of Arctic sea ice on the Arctic energy budget and on the climate of the Northern mid-latitudes. Clim Dyn (EC-Earth Special Issue). doi:10.1007/ s00382-012-1353-9

Singarayer JS, Bamber JL, Valdes PJ (2006) Twenty-first-century climate impacts from a declining Arctic sea ice cover. J Clim 19:1109-1125

Slonosky VC, Mysak LA, Derome J (1997) Linking Arctic sea-ice and atmospheric circulation anomalies on interannual and decadal timescales. Atmos Ocean 35:333-366
Smith D, Scaife A, Eade R, Knight J (2014) Seasonal to decadal prediction of the winter North Atlantic Oscillation: emerging capability and future prospects. Q J R Meterol Soc 142(695, Part B):611-617. doi:10.1002/qj.2479

Sterl A, Bintanja R, Brodeau L, Gleeson E, Koenigk T, Schmith T, Semmler T, Severijns C, Wyser K, Yang S (2012) A look at the ocean in the EC-Earth climate model. Clim Dyn 39:2631-2657. doi:10.1007/s00382-011-1239-2

Strong C, Magnusdottir G (2008) Tropospheric Rossby Wave breaking and the NAO/NAM. J Atmos Sci 65:2861-2876

Tietsche S, Notz D, Jungclaus JH, Marotzke J (2011) Recovery mechanisms of Arctic summer sea-ice. Gephys Res Lett 38:1-4, Article ID L02707. doi:10.1029/2010GL045698

Timmermans M, Proshutinsky A, Krishfield R, Perovich DK, Richter-Menge JA, Stanton TP, Toole JM (2011) Surface freshening in the Arctic Ocean's Eurasian Basin: an apparent consequence of recent change in the wind-driven circulation. J Geophys Res 116:1-17, Article ID C00D03. doi:10.1029/2011JC006975

Uppala et al (2005) The ERA-40 re-analysis. Q J R Meteorolog Soc 131(2005):2961-3012. doi:10.1256/qj.04.176

Venegas S, Mysak LA (2000) Is there a dominant timescale of natural climate variability in the Arctic? J Clim 13:3412-3433

Walsh JE, Anisimov O, Hagen JOM, Jakobsson T, Oerlemans J, Prowse TD, Romanovsky V, Savelieva N, Serreze M, Shiklomanov I, Solomon S (2005) Cryosphere and hydrology. In: Symon C, Arris L, Heal B (eds) Arctic climate impacts assessment, ACIA. Cambridge University Press, Cambridge, pp 183-242

Wang X, Key JR (2003) Recent trends in Arctic surface, cloud, and radiation properties from space. Science 299(5613):1725-1728. doi:10.1126/science. 1078065

Woollings T, Hoskins B, Blackburn M, Berrisford P (2008) A new rossby wave-breaking interpretation of the North Atlantic oscillation. J Atmos Sci 65:609-626. doi:10.1175/2007JAS2347.1

Yang S, Christensen JH (2012) Arctic sea ice reduction and European cold winters in CMIP5 climate change experiments. Geophys Res Lett 39(20). doi:10.1029/2012GL053338 